Article

\title{
Expansive Social Learning, Morphogenesis and Reflexive Action in an Organization Responding to Wetland Degradation
}

\author{
David Lindley ${ }^{1,2, *}$ and Heila Lotz-Sisitka ${ }^{2}$ \\ 1 Freshwater Programme, World Wide Fund for Nature (WWF), P.O. Box 5, Braamfontein 2017, South Africa \\ 2 Environmental Learning Research Centre, Department of Education, Rhodes University, P.O. Box 87, \\ Grahamstown 6140, South Africa \\ * Correspondence: dlindley@wwf.org.za
}

Received: 29 April 2019; Accepted: 18 June 2019; Published: 5 August 2019

\begin{abstract}
This study (conducted as PhD research at Rhodes University, South Africa) describes a formative interventionist research project conducted to explore factors inhibiting improved wetland management within a corporate plantation forestry context and determine if, and how, expansive social learning processes could strengthen organizational learning and development to overcome these factors. A series of formative interventionist workshops and feedback meetings took place over three years; developing new knowledge amongst staff of Company $\mathrm{X}$, and improved wetland management practices. Through the expansive learning process, the tensions and contradictions that emerged became generative, supporting expansive learning that was reflectively engaged with throughout the research period. The study was== supported by an epistemological framework of cultural historical activity theory and expansive learning. Realist social theory, emerging from critical realism, with its methodological compliment the morphogenetic framework gave the research the depth of detail required to explain how the expansive learning, organizational social change, and boundary crossings that are necessary for assembling the collective were taking place. This provided ontological depth to the research. The research found that expansive learning processes, which are also social learning processes (hence we use the term 'expansive social learning', supported organizational learning and development for improved wetland management. Five types of changes emerged from the research: (1) Changes in structure, (2) changes in practice, (3) changes in approach, (4) changes in discourse, and (5) changes in knowledge, values, and thinking. The study was able to explain how these changes occurred via the interaction of structural emergent properties and powers; cultural emergent properties and powers; and personal emergent properties and powers of agents. It was concluded that expansive learning could provide an environmental education platform to proactively work with the sociological potential of morphogenesis to bring about future change via an open-ended participatory and reflexive expansive learning process.
\end{abstract}

Keywords: expansive social learning; organizational learning and development; social change; environmental management

\section{Introduction}

Bruno Latour [1] in his work on the politics of nature asks how humans in their individual and organizational contexts ought to be re-thinking their notion of the collective. He suggests assemblages of human and non-humans viewed through the lens of 'matters of concern'. One such matter of concern is wetland management. Wetlands provide a host of ecosystem services and goods; they are highly valuable to society and its well-being and have been described by scientists as one of the most 
important ecosystems on our planet [2]. Yet some key individuals and collective agents in organizations that manage large tracts of land, such as in plantation forestry, continue to not always recognize their value to the company and broader society. They rather see wetlands and their ecosystem services as a 'matter of fact' [1] removed from and separate from the business of, for example, producing forestry products and paper. Despite the high value of wetlands to society, global wetland and river degradation over the previous 100 years has been alarmingly high [3]. In South Africa alone, about half of the country's wetlands are being lost due predominantly to a range of different types of development [4]. They are the most threatened ecosystem in South Africa today [5], with over $52 \%$ of wetlands being critically endangered or endangered. Latour [1] suggests that militant political ecologists, engaged in actions that assemble a collective of human and non-humans in relational formations are needed if the ecological crisis, and by association the crisis of human futures is to be addressed. We propose this as an innovative lens for re-thinking organizational development, but in conducting this research, we sought ways of demonstrating such a process of political ecology action and change at an organizational level, with a specific focus on the expansive social learning potential that emerged from our formative interventionist research approach.

In this research we use cultural historical activity theory, complemented by a socio-material critical realist ontological framework to explore how agency for the kind of action-centered political-ecology that Latour [1] refers to, can be cultivated in organizations such as Company $X$ (the focus of this case study). Company $X$ is an international packaging and paper company that manages approximately 300,000 ha of land in South Africa for plantation forestry. After over a decade of the conservation organization, WWF-South Africa, working with Company $X$ to improve its wetland management, wetland sustainability practices were still not integrated into the broader forestry operations. This occurred despite some significant cases of successful wetland rehabilitation, and despite the fact that Company $\mathrm{X}$ was 'aware' of the significance of wetlands and water security to their core business. In environmental education too, we found that while there is strong support for social learning, action and change-oriented outcomes seldom result, especially at an organizational level [6-8]. Harold Glasser [9] points to the massive gap that exists between intention and action as often found in environmental education program outcomes. How individual and/or group-based learning interactions translate to the collective, at the level of organizational change was a key issue probed in this study.

\subsection{The Importance of Wetlands to Company X's Forestry Operations and its Impacts}

Wetlands provide a host of ecosystem services and goods [10]. Those applicable to wetlands in South Africa, and more specifically to Company X, include the ability of wetlands to purify water, regulate its flow, recharge groundwater aquifers, attenuate floods, and control erosion. Wetlands also provide natural resources for use by communities living nearby, including building materials, fish, potable water, material for making tourist and traditional crafts, livestock grazing, and subsistence agriculture. However, the species of alien (originating from outside South Africa) plantation trees are all highly invasive in South Africa, if not managed appropriately. These include eucalyptus, pine, and wattle tree species, which are all high water users compared to the natural grassland vegetation they have replaced [11,12]. The interception and use of rain and groundwater by plantation trees in the catchment of a river and wetland is so significant that the South African Department of Water Affairs and Forestry declared the plantation forestry industry as a "stream flow reduction activity" [13]. This is the only crop in South Africa legislated as such, and stringent regulation is required by government for those wanting to grow plantation trees.

A summary of the key wetland related social-ecological issues of importance to Company $X$ include [14,15]: (1) Plantation trees incorrectly planted in, or to close to wetlands, result in wetlands gradually drying up as the trees grow and mature; (2) alien invasive plant species invading wetland and riparian zones due to the disturbances caused directly or indirectly by plantation forestry operations; (3) inappropriate burning practices of wetlands for firebreaks to protect the plantations can lead to 
reduced biodiversity, gully erosion in the wetlands, destruction of peat soils, and a loss of ecosystem integrity; (4) inappropriate road design and poor maintenance of roads in the catchment, as well as those crossing wetlands causing erosion and/or excesses sedimentation of the wetland; (5) drains dug by previous landowners for commercially cultivating dryland crops, alter the hydrology and therefore integrity of the wetlands; and (6) excessive grazing by livestock owned by tribal communities living either on or adjacent to the land managed by Company $\mathrm{X}$, leading to gully erosion occurring in the wetland if not managed wisely, and drying out of the wetland.

\subsection{Company X Staff Responsible for Wetland Management}

Wetland management on Company X's managed land is shared between the following three professional job descriptions: (1) Silviculture foresters: Who are the farm managers responsible for growing and harvesting the plantation trees that are required by Company X's pulp mills for manufacturing packaging and paper products. Their professional training and skills are predominantly agronomic, as required for growing and harvesting plantation trees. The foresters have the responsibility of managing the land on which the plantation trees are grown, and are also the custodians of all open natural areas that have not been planted to trees, such as wetlands, grasslands, and indigenous forests. (2) Environmental specialists: Who support foresters with the environmental expertise needed to manage the areas not under plantation trees, including wetlands. Their skills and education are in conservation and environmental sciences. Since environmental management is a broad field of knowledge, they require the support of subject specialist where required, such as for wetlands. (3) Community engagement facilitators: Who engage with the tribal communal land users living adjacent to or who have settled on Company $X^{\prime}$ 's land over the past decades. They assist the foresters with any social issues that may arise between the community and the company, and their knowledge, education, and skills originate mainly in the social sciences.

\subsection{Previous Wetland Capacity Building Efforts Had Not Resulted in the Expected Long Term Change}

Prior to this study, past approaches of how the WWF had worked with Company $X$ environmental and forestry staff to develop wetland capacity over more than a decade, had a simplistic understanding of how adults learnt and the dynamics of social change. This was based on 'gut feel' and what WWF staff thought would work best. This led to the false assumption that the logically thought out activities and ways of working that had led to the development of wetland interest and passion, wetland knowledge, and wetland skills, would automatically result in the long term social change required to improve wetland management practices.

These past approaches of WWF support had not resulted in the changes required for Company $X$ to maintain and improve the integrity of its wetland over the long term, despite Company $\mathrm{X}$ having environmental and wetland policies promoting better environmental and wetland management as responsible plantation forestry practices. Over the past 16 years, the collaborative work of Company $\mathrm{X}$ and WWF has contributed to several important successes in responding to the above-mentioned social-ecological issues. These include some significant achievements, especially in wetland delineation and the removal of trees incorrectly planted in wetlands and their adjacent buffer zones, but also wetland rehabilitation and the development of a wetland management policy [14]. However, despite the huge amount of collaborative work over the years, collectively these individual actions and achievements did not appear to have resulted in the human capacity development and institutional changes necessary to support a continual and long-term improvement in wetland integrity and sustainability practices. The expectation was that after so many years of support from WWF, Company $X$ staff would be well capacitated, wetland management would be well integrated into forestry operations, and most importantly, the condition of the wetlands on Company $\mathrm{X}$ landholdings would be continually improving. However, the findings from a State of Wetlands Report that assessed the health of key wetlands on Company X landholdings, from 2009-2010, indicated that overall wetland condition was not improving [15]. The main challenges still being faced included those practices 
and activities that continued to have a negative impact on wetland integrity including incorrect burning practices for fire breaks, poorly managed livestock grazing, road crossings inappropriately constructed through wetlands, and the lack of continued management of alien plant control programs in and around wetlands [15]. Earlier preliminary research had shown that even after all the years of working together with Company $\mathrm{X}$ with initial successes, a few of which continue today such as the withdrawal of timber from wetlands, Company $X$ had yet to develop an integrated approach to wetland management within its forestry operations [16]. A broad range of long-term wetland sustainability practices had not been significantly integrated into the field operations of those staff that are responsible for wetlands. This included the foresters, environmental specialists, community engagement facilitators, and operations management.

\subsection{The Need for the Research}

A number of factors within Company X, may have contributed towards inhibiting the human capacity development and institutional changes necessary to support a continual and long-term improvement in wetland integrity and management. These could have included a lack of an integrated approach to wetland management; a long-term restructuring of the company; or institutional factors inhibiting an enabling environment for wetland learning and management to take place in. No one was sure if this is the case or not, or if there are other factors at play [16]. It was therefore important to work with Company $\mathrm{X}$ staff in a more informed way; through an exploratory research-based process to identify, understand, and work towards overcoming what was really inhibiting the improvement of long-term wetland management. The research was therefore oriented to support expansive social learning processes between those Company $\mathrm{X}$ staff who have a responsibility to manage wetlands, to identify factors inhibiting wetland management, better understand the root causes of them, and develop solutions [17]. The purpose of the research was to investigate adult learning within an organizational setting, and understand how the emergence of staff agency can support organizational learning and development and change to improve wetland management. The aim of the research was therefore not only to identify and deal with the inhibiting factors, but also to rather understand, if changes happened, the logic behind the realities of how the change processes emerged. This would then explain if expansive social learning could strengthen wetland sustainability practices of a large corporate landowner, and if so, how it could do this.

\subsection{The Following Three Research Questions were Used to Guide the Research}

1. What tensions and contradictions exist in wetland management in a plantation forestry company? [17]

2. Can expansive social learning begin to address the tensions and contradictions that exist in wetland management in a plantation forestry company, for improved sustainability practices? [17]

3. Can expansive social learning strengthen organizational learning and development, enabling Company $\mathrm{X}$ to improve its wetland sustainability practices, and if so how does it do this? [17]

\subsection{Organizational Learning}

Since this research investigated adult learning within an organizational setting, and how the emergence of staff agency can support organizational development and change to improve wetland management, it is important to explore what some of the literature says about how learning takes place in organizations. This requires exploring the concept of organizational learning. There is a huge body of literature on how learning helps organizations to change [18-23]. A key thread running through much of this research is understanding both how people learn as individuals in organizations, as well as the notion that organizations can 'learn' or change through staff learning and sharing their knowledge with others in the organization resulting in changes that reflect this learning taking place at the organizational level [23]. 


\subsubsection{The 'Split' in Organizational Learning and the Learning Organization}

Due to organizational learning $(\mathrm{OL})$ attracting researchers from a variety of disciplines, including economics, psychology, sociology, management, and education, each with differing ontological and epistemological positions, the field has become conceptually fragmented and highly debated [19,23,24].

As a result of this debate, two distinct branches of literature began to develop along the lines of the two concepts of OL and that of the learning organization (LO) [19,23]. The former focuses on exploring and understanding the processes of individual and collective learning in the organizational context. It is therefore descriptive and largely represented by academics. The second group takes a LO perspective, which comes across as being more prescriptive and practical, and is mainly represented by consultants (or consulting academics) who offer and develop models and tools to support organizations develop policies and strategies to specifically promote and institutionalize learning within them. This helped organizations to adapt to uncertainty, increase their business performance and therefore gain competitive edge.

\subsubsection{The Popularity of the Learning Organization and Criticisms of It}

The LO concept gained significant popularity, especially in the context of the global economic recession of the late 1980s and early 1990s, and with it a proliferation of publications during what is described as the LO golden era of the 1990s [23]. Learning therefore became a key issue for organizational sciences and managers. The popular writings of Tom Peters [25] and Peter Senge [18], among others, became very compelling for guiding corporate organizations to develop into learning organizations, to improve their productivity and profitability. With this surge of interest in LO and abundant publications, came a confusing assortment of definitions and the resulting conflation and mixing up of the concepts of OL and LO. This gave rise to an increasing number of critical reviews in the literature [20,23,26-28], with some notable comments. For example, Rebelo and Gomes [23] somewhat scathingly noted that during the late 1990s and early 2000s "these concepts seem to have been turned upside down, characterized by criticisms of the concepts themselves, of the messianic idea that LO concept is the salvation of organisations, of the fashion effect that has contributed, to a great extent, to weak conceptual clarification and to a narrow and unsubstantiated empirical basis..." (p. 299).

\subsubsection{Individual and Collective Learning in Organizations}

Elkjaer's [29] perspective on the debate between OL and LO neatly encapsulates one of the key elements of learning in organizations, that Fenwick [26] also touched on, and is important in differentiating between OL and LO. Elkjaer is so emphatic on the importance of the social aspect of OL that she insists "a theory on OL/LO must take its point of departure in a social learning theory. In other words, it should acknowledge that learning in organisations also has a social aspect. It is not merely an individual affair, as it takes place within the realm of collective human actions and interactions" [29] (p. 76). This is a key point that Elkjaer uses to distinguish between authors such as Senge who see OL and LO as a management tool and requires that organizations be understood as systems, and those who see OL from a socio-cultural learning perspective (described in Section 1.6.4) such as Brown and Duguid [30]. Much like Fenwick [26], Elkjaer [29] believes that when the concepts of OL/LO are used as tools to bring about organizational change, these tools are used as instruments to control organizational processes and bring members' behavior into line with that of the organization. This attempt to alter the thinking, values, beliefs, and therefore actions of people, is contrary to the social learning orientation to OL.

Authors such as Senge, who see OL/LO as a management tool, base their work on needing to see organizations from a systems perspective. This Senge says can be used as a framework for understanding interrelationships and patterns of change, as well as the structures that lie beneath complex organizational issues in order to see a picture of the whole organization [18]. However, 
Elkjaer [29] insists that this perspective is founded on learning which concentrates on individual cognition. She claims that although it may seem a contradiction in light of systems thinking seeing the whole and not the parts, "it is as if the systems perspective, through its reification of organisational structures and processes, has lost sight of the importance of collective human actions and interactions and, thus of a social theory of learning. The organisational perspective in this approach becomes the perspective of individuals who-separately-encounter organisational structures and processes" [29] (p. 78). Through this statement Elkjaer suggests that the concept of LO faces, "ontological collapse" as described by Lotz-Sisitka, Mukute, and Belay [31]. She therefore sees the management tool approach of LO as being based on the fact that learning takes place as individual cognition through the acquisition of skills and knowledge. This is contrary to the socio-cultural approach to OL that rather sees learning as taking place through social interaction situated within the work environment of the organization [21].

Lee and Roth [32] take the discussion on individual and collective learning further, concluding that it is problematic to separate individual and collective learning. They consider that researchers investigating learning in organizations have sidelined how organizations and their staff presuppose each other, and rather deduced that organizations are structures that determine the actions of the staff. Lee and Roth [32] conducted a longitudinal ethnographic study attempting to understand who learns in organizations and how. This study demonstrated "a way of framing individual and collective learning as coinciding as soon as individual and collective are theorized dialectically: in each individual act, the organisation is both presupposed and constituted" (p. 104). Thus the organization and its staff are interdependent. They therefore saw no separation between individual and collective learning because they both exist dialectically, since individuals make up an organization, which acts back on the individuals by either enabling or constraining them. Learning is therefore seen as a result of the interaction between the organizational structure and agency of individuals, without structure determining agency. Although Lee and Roth [32] see actions as taking place collectively, they state that it is the individuals that make these actions happen. From these actions outcomes emerge, which open up new possibilities for further actions in the future. This reproduces existing possibilities, while also presenting new ones, therefore demonstrating that learning within organizations is a dialectical process. They conclude that "dynamic and expansively learning organisations presuppose dynamic and expansive individuals; dynamic and expansive individuals presuppose dynamic and expansively learning organisations" [32] (p. 104).

\subsubsection{The Socio-Cultural Approach to Organizational Learning}

This research, constituted as a case study of a plantation forestry company [17], sought to understand if organizational learning and development can be strengthened within the company to improve its wetland sustainability practices, and if so, how this happened and what learning and development processes were playing an important role. For this reason it was important to follow the OL literature. Within the OL branch of literature, Easterby-Smith and Araujo [19] identified a group of researchers who have chosen to understand organizational learning as being socially constructed, as a political process that needs to be engaged with rather than avoided and nullified; and learning is seen as a cultural artifact that is considered as part of the organizational culture. They therefore rather focus on social and cultural processes, and understanding how people make sense of experiences in the workplace arising from both tacit and explicit sources. It is this approach to organizational learning that was chosen to support this case study.

Boreham and Morgan [24] define this socio-cultural approach to OL as learning that is "perceived as being embedded in social and cultural contexts, and best understood as a form of participation in those contexts. This concept of learning implies the simultaneous transformation of social practices and the individuals who participate in them, and thus the social and individual dimensions of learning are mutually constitutive" (p. 308). Boreham and Morgan [24] believe that dialogue is the foundational process of learning at its core, which is contrary to the belief of many American management theorists, such as Senge [18] discussed in Section 1.6.3, who use dialogue as a tool at specific stages in the 
organizational learning process. Importantly, they also identify relational practices as being the social structure to integrate dialogue and organizational learning through promoting staff collaboration. Reporting from a case study they undertook, Boreham and Morgan identified three relational practices as being crucial for the pedagogy of organization learning in terms of participation in these practices: Firstly, the space for staff to create shared meaning needs to be created; secondly, power relationships need to be re-constituted; and, thirdly cultural tools need to be provided to mediate learning. They found that if staff of an organization were the carriers of these practices, the organizational culture was shaped to sustain a period of learning when staff went about their everyday interactions.

This socio-cultural approach that has been described above would broadly include the work of Engeström [33], Lave and Wenger [34], and Elkjaer [21,29]. Within these approaches to organizational learning, we focused on the literature exploring expansive learning after Engeström [33], as these organizational learning theories are of most relevance to this research. Engeström has developed a special kind of organizational learning called 'expansive learning' that is based on cultural historical activity theory (CHAT) [33,35]. Its theoretical foundations shape its methodological orientation. We extended interpretation of data generated from this approach to organizational learning with critical realist theories of structure and agency, as outlined below.

\section{Methodology}

The following theoretical frameworks with their associated and well articulated complimentary methodologies were used to guide the research:

\subsection{CHAT and Expansive Learning}

The research explored if a number of Company $X$ staff who have a responsibility for wetlands, can be supported through formative interventionist research to identify and deal with factors seen to be inhibiting wetland sustainability practices. In order to do this it was important to probe beneath the surface of these factors, and identify the root causes that have inhibited transformation so far. According to Engeström [33,36,37] and Daniels [38] these causes are most likely to be related to various tensions and contradictions of cultural and historical origin. For this reason, the epistemological framework for the research was provided by Engeström's [33,36,37] cultural historical activity theory (CHAT) and a special type of organizational learning called the theory of expansive learning [39] that is based on CHAT. These two theories supported the formative interventionist research approach, which mobilizes collective agency to improve wetland sustainability practices, in response to various tensions and contradictions identified in the interacting activity systems of the foresters, community engagement facilitators, and environmental specialists.

\subsubsection{Models of CHAT Used}

Second generation CHAT (Figure 1) was used to develop a contextual picture of the three activity systems of the professional groupings responsible for managing Company $\mathrm{X}^{\prime}$ s wetlands (the foresters, community engagement facilitators, and environmental specialists). This supported the search for insights into the relationships and interactions that existed within each of the cultural and historically constituted activity systems, through examining: The relationships and interactions between subjects and the objects they were working on (better wetland management); mediating tools and artifacts that were used; rules that governed the use of the system; the community of practice involved in the system; and the division of labor among those working in the system. 
What mediating tools and artifacts are used in this system?

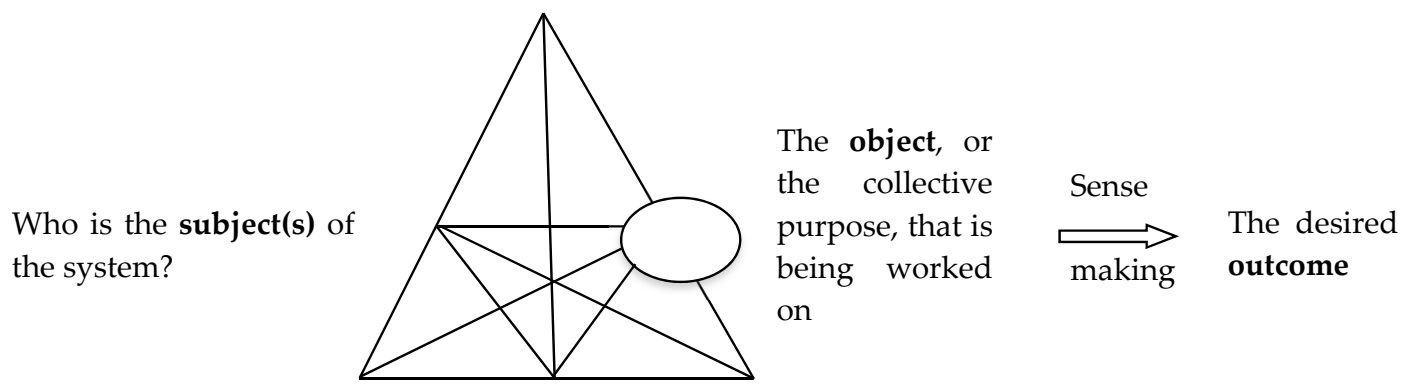

What are the rules that govern the use of the system, both the official and ones that do not Who is the community of practice in this system?
What is the division of labor, both the horizontal and vertical hierarchy? always get talked about?

Figure 1. Second generation mediating triangle of a cultural and historically constituted activity system, adapted from [33] p. 178.

The third generation CHAT (Figure 2) focuses on interactions that occur between two or more second generation activity systems, that are working on a shared object, and the complexities that arise when their boundaries meet and are crossed [40]. This was used to examine the interactions that occurred when the separate activity systems of the foresters, community engagement facilitators and environmental specialists meet in order to manage wetlands on Company $\mathrm{X}$ land.

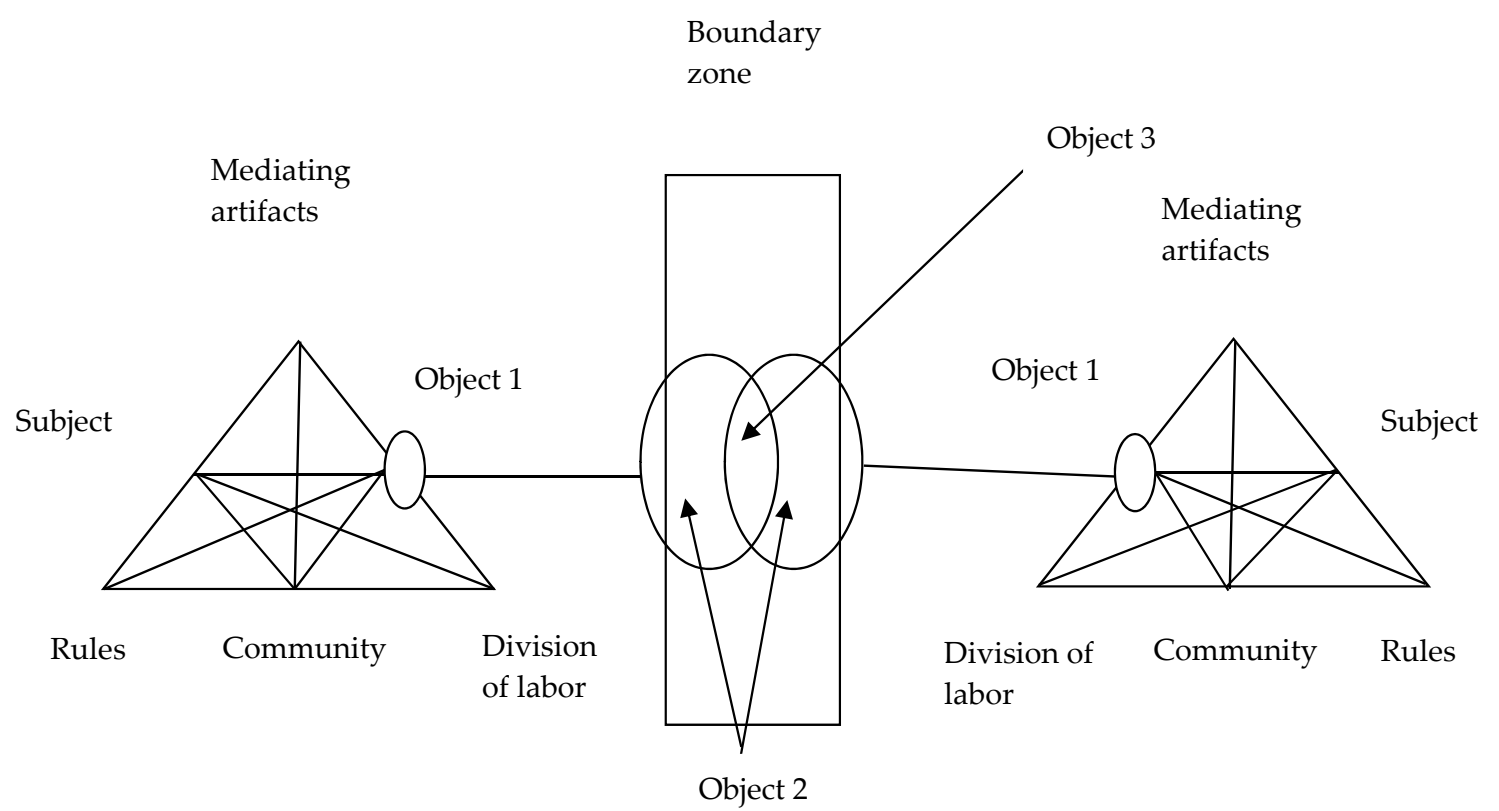

Figure 2. Third generation activity theory: Two activity systems with a partially shared objective as a minimum unit of analysis, adapted from [39] p. 14.

It is during this interactive boundary crossing that most of the learning occurs as the object of an activity system moves from being an object that is not reflected upon and simply worked upon by the subject(s) of an activity system (object 1 in Figure 2), to being an object that is collectively worked on by the interacting activity systems, and therefore becomes collectively meaningful (object 2), to lastly evolving to be an object that is co-constructed by the interacting activity systems and becomes a new reconceptualized object (object 3) [37]. The unit of analysis in third generation activity theory becomes 
the joint activity or practice that the interacting network of activity systems are acting on, instead of the individual activity as in second generation CHAT [38]. In this way the analysis looks at social transformation through analyzing the structure of the social world and the dissonance that occurs in social practice, which is created by tensions and the resulting contradictions that occur within and between activity systems [38]. It is these contradictions that when understood and worked with are considered to be the triggers of change and development [37] that result in reconceptualization of the object.

\subsubsection{A Brief Introduction to Expansive Learning}

Engeström [37] believes that most standard theories of learning focus on learners or organizations acquiring stable knowledge that is reasonably defined from a more learned teacher who knows what needs to be learned, and this results in some lasting change in behavior. However, he poses the problem that much of the learning that takes place in organizations violates this presumption, as in the workplace people are often learning knowledge that is not stable or known beforehand. The combined training of individual staff to develop new skills and knowledge will not help face these learning challenges. The problem is therefore an organizational learning one that cannot be solved by training individuals only. Engeström says that it is important to learn new forms of activity that have not yet been identified, resulting in learning as the new forms of activity are being created, without a more knowledgeable teacher who knows the answer, although external knowledge of the activity may exist elsewhere. Engeström is also adamant that "theories of organizational learning are typically weak in spelling out the specific processes or actions that make the learning process" [37] (p. 150). He therefore put forward the theory of expansive learning to understand the type of learning required to learn new knowledge and new forms of activity that are not previously known, and the expansive learning cycle as a methodology for empirically researching organizational learning.

\subsubsection{Expansive Learning Cycle as a Methodology for Applying CHAT and the Theory of Expansive Learning}

The theory of expansive learning, and its methodological component the expansive learning cycle, provided a good insight into the process and actions of how organizational learning and change can be catalyzed and analyzed through identifying and dealing with the organizational contradictions that had accumulated historically over time. The expansive learning cycle is implemented through a series of interventionist workshops and actions modeled on the Change Laboratory Workshop methodology [40], and is based on seven steps or learning actions (Figure 3; [40]) which are summarized as:

(1) Firstly, current practices are questioned based on ethnographic evidence. Due to the multiple viewpoints of participants, this learning action of questioning of current practice can be conflictual in nature as it supports practitioners to focus on the root causes of the problems that are preventing transformation from occurring. This is a key step in the expansive learning cycle, as Engeström [37] believes that most models of organizational learning are based on the assumption that what needs to be created and learnt is a decision of management and not the staff that report to them. Hence the first stage of staff learning is unproblematic and conflict free. This, Engeström says, is exemplified in Nonaka and Takeuchi's well-known model of organizational learning that is founded on conversions between explicit and tacit knowledge [37]. In stark contrast to these other models of OL, the first stage of expansive learning is rich in conflict, when existing standard organizational practices are rigorously questioned. (2) This vigorous questioning leads to the second step or learning action of deeply analyzing the cultural and historical origins of current practices following onto more detailed and better articulated questioning of the existing practices. The questioning and analysis are aimed at identifying and defining problems, and most importantly the tensions and contradictions that lie behind them. It is out of this dialogic questioning that new opportunities and more informed practice potentially begin to emerge. (3) The third step or strategic learning action is modeling of new solutions and alternative ways of working and learning. (4) The fourth step or learning action in the expansive 
learning cycle examines the new model through critical discussion to better grasp its viability. (5) The fifth step or learning action relies on implementing the model and monitoring the effectiveness of it. (6) The sixth step or learning action involves reflecting on the process of the expansive learning cycle and its outcomes. (7) Lastly, the seventh step or learning action revolves around consolidating the practice. These steps are typically supported via change laboratories, which are workshops that take place over time, which allow people time to engage in these learning actions, and reflect on them as they proceed. Developed in the mid 1990s by Yrjö Engeström and co-researchers, change laboratory methodology is typically conducted in an activity system that needs significant transformation. The Change Laboratory has been designed as a method to complement Engeström's methodological expansive learning cycle and has been fine-tuned by Engeström over the past 20 years [40].

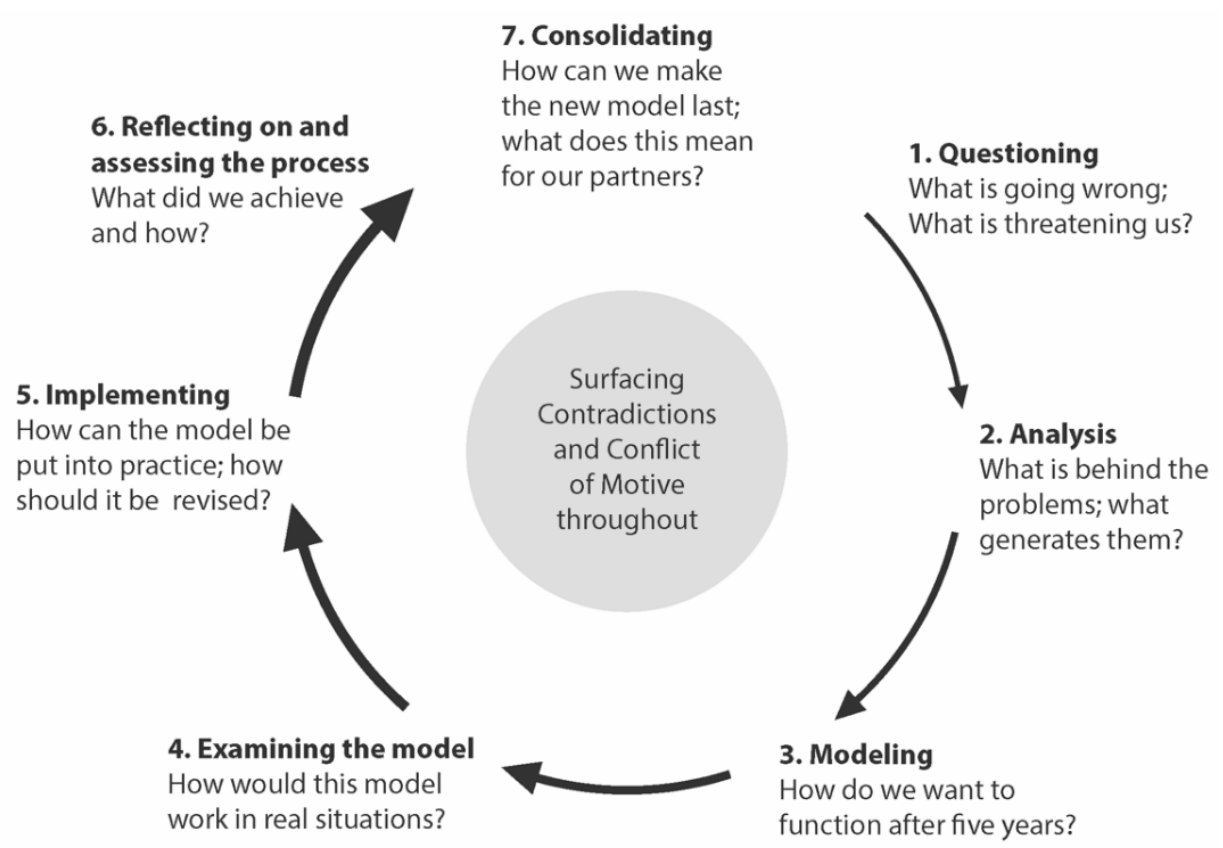

Figure 3. Stages of the expansive learning framework, adapted from [40] p. 8.

It is important to note that although the seven steps of the expansive leaning cycle may appear to occur in a logical sequence, they do not necessarily follow each other. Progress in the cycle from one step to the next is not deterministic, and it may actually fluctuate between steps, be obstructed, or revert back to a previous step [35,40]. The expansive learning cycle is not a cycle of continuous successive steps, but rather one of smaller cycles within a larger one, with key actions attempting to understand the direction of change being repeated as multiple discontinuities arise [41].

\subsection{Critical Realism}

The socio-material philosophy of critical realism and its stratified ontology, which differentiates between the Empirical, the Actual, and the Real after Bhaskar [42] was used to provide ontological depth perspective to the research. It helped to more deeply understand the structural generative mechanisms at the level of the Real that gave rise to deep seated and long-standing contradictions, events, and empirical experiences of such events as found in the organization, especially in relation at the interface of mainstream commercial forestry practice and wetland management. Bhaskar [42] sees the realist ontology as consisting of three stratified levels or domains. The first layer of reality being the 'Real', which is whatever exists, despite whether people are aware of it or not. The Real is known as an intransitive, or unchanging world, which is made up of generative mechanisms such as structures with properties and causal powers. This world is "relatively independent of the patterns of events and the actions of men alike" [42] (p. 46). It is from these generative mechanisms that the 
second layer emerges, that of the 'Actual', which is the reality of events that happen when (and if) the generative mechanisms of the Real are activated. As with generative mechanisms, Bhaskar believes that "events must occur independently of the experiences in which they are apprehended" [42] (p. 46). It is from these events, that the third 'Empirical' layer of reality emerges, which essentially is the realm of human experiences and observations. The Empirical is known as the transitive, or changing world, and is made up of our multiple and varied socially determined conceptions of reality.

It is important to note that both the generative, or causal, mechanisms of the Real and the events of the Actual are not necessarily reflected in the experiences of the empirical [43]. Therefore one cannot rely on the Empirical to reveal the causal effects of phenomena. As Sayer [44] highlights, although seeing or naming things makes us more confident that something exists, this does not mean that if we cannot see or name it, it does not exist. He explains that in light of this, one of the most distinctive features of realism is its acceptance of causal criterion. Therefore, reasoning can be made for the existence of something unobservable, by seeing the effects of it.

\subsection{Realist Social Theory}

CHAT and expansive learning provided useful interpretive and methodological process guidance for engaging with contradictions emerging in the context, leading to a process of expansive learning over a period of five years. However further analytical tools were necessary to explain how the expansive learning was related to the emergence of organizational social change and the boundary crossings that are necessary for assembling the collective: Human and non-human relations as mentioned above. While change at an organizational level was visible (see results below), it was not clear to see how this emerged, therefore we drew on Archer's [45] non-conflationary realist social theory that provides tools for explaining how and why social change (in our case social-ecological change) occurs in organizations. Archer's realist social theory, which developed out of critical realism as an ontologically located theory of how and why social change occurs, takes account of socio-cultural interaction, structural interaction, and the formation of new knowledge and practice. Social realists believe that the agency of people is influenced by the properties and powers of social structures and cultural systems (together known simply as structures or 'parts' as Archer calls them) within their context; but through interaction with these structures, people can also develop the properties and powers to change them [45]. In this way social realists believe that although society shapes the agency of people, people can in turn develop the agency to act on and change society, which aligns with the OL argument of Lee and Roth cited above. Thus human action is conditioned, but not determined by pre-existing social structures. This strengthens interpretation of changes emerging from CHAT and expansive learning analyses.

Archer holds that (using a methodological approach of analytical dualism) that structure and agency are separable by definition because of these properties and powers that are unique to each of them, and their emergence from each other justifies their differentiation. Therefore understanding the interplay between them both becomes vital [45]. She suggests: "explanation[s] of why things social are so and not otherwise depends on an account of how the properties and powers of the 'people' causally intertwine with those of the 'parts' over time (T1-4)" [45] (p. 15). Archer strongly believes that despite the independence of individuals, social structures and cultural systems with each possessing distinct properties and powers operating at the level of the Real, both social structures and cultural systems are the result of social relations that can only be elaborated through the agency of individuals. Archer is quite clear on this when she explains that "structural and cultural properties (SEPs and CEPs) only emerge through the activities of people (PEPs), and they are only causally efficacious through the activities of people" [46] (p. 307). She goes on to explain that structural and cultural properties emerge from a number of intended and unintended consequences, and that it is only when these properties have emerged, that they can exercise their powers of constraint and enablement by molding the situations that people find themselves in. Carter and New [47] provide a good example of a property of social structures and cultural systems as being their anteriority; meaning they can exist prior to us 
being born into the world, such as the linguistic and legal systems that came before us. Another key property of these structures is that they are relatively enduring and long lasting. These properties then generate the powers of social structures and cultural systems to enable and constrain certain actions, over generations or even centuries. As an example of key properties of people that are relevant to agency, Carter and New cite reflexivity, self-consciousness, emotionality, and intentionality. These properties then allow people certain powers of agency. It is these causal powers which, Archer says, allow people to critically reflect on their social context, develop alternative solutions to it, learn and act reflexively to collaboratively transform it with other people, rather than being passive recipients of it [46].

\subsubsection{Morphogenetic Framework as a Methodology for Applying Realist Social Theory}

Archer puts forward the morphogenetic framework as the way of operationalizing analytical dualism where the analysis of structure and agency are done separately in order to understand the interplay between them [45]. She recommends that the social analyst requires practical guidelines to analyze and explain this interplay between the pre-existing social structures with their properties and causal powers, and the people with their associated properties and causal powers. She has therefore put forward her morphogenetic framework as a methodology to analyze this interaction over time, and to determine why change happens or does not happen. The basic morphogenetic cycle (Figure 4) is seen as three never-ending phases of (1) structural conditioning, (2) socio-cultural interaction, and (3) structural elaboration or reproduction [45].

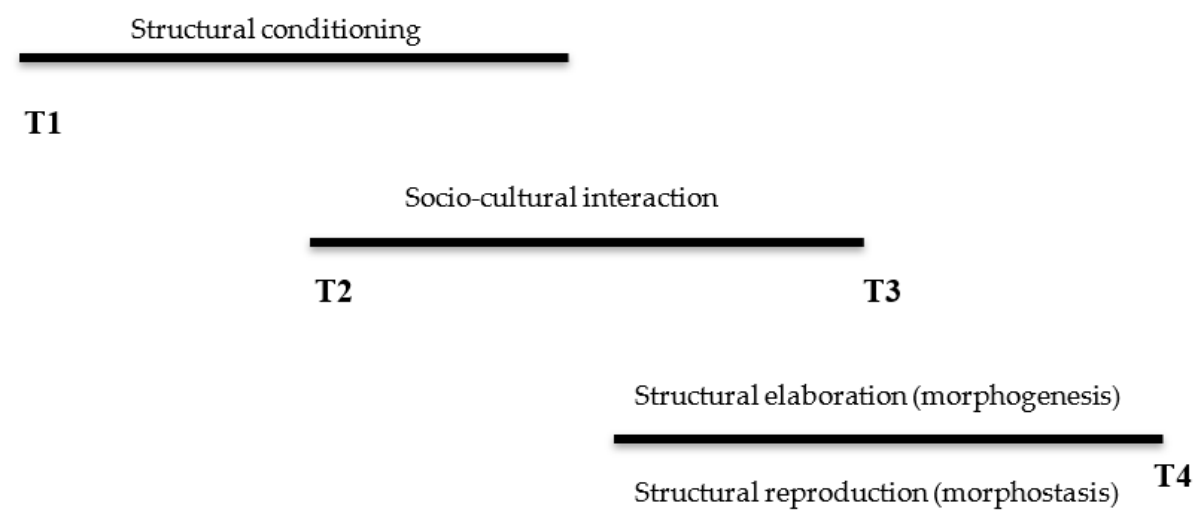

Figure 4. Three phases of Archer's basic morphogenetic and morphostatic cycle, where ' $\mathrm{T}$ ' is time, adapted from [45] p. 157.

Importantly, Archer stresses that the morphogenetic framework is founded on two basic suppositions: "(1) That structure necessarily pre-dates the action/s leading to its reproduction or transformation. (2) That structural elaboration necessarily post-dates the action sequences which gave rise to $\mathrm{it}^{\prime \prime}$. [45] (p. 15). In this way social structures are the results of previous social interactions between people in the past who have conditioned the context in which people currently find themselves. The way in which the current people respond to this context, will then shape the social structures that future people will find themselves in [48]. However, the ability of people to respond will be limited by the 'degrees of freedom' that the social structures allow, which sets the boundaries of agency [45]. The temporal dimension is therefore a critical part of the morphogenetic framework.

Following five years of expansive social learning in Company $X$ (with the first year focusing on contextual profiling and activity system identification), we analyzed the processes and outcomes of the expansive learning process (see research process below) to a morphogenic analysis, to identify what changes had actually taken place at the organizational level and how these had emerged; and if they reflected social-ecological change or a stronger 'assemblage of the collective'. 


\subsubsection{Highlighting the Social Learning in Expansive Learning}

It is important to note, as outlined in the introduction, that in this study, the terms 'expansive learning' and 'expansive social learning' have both been used. As the research played out and the findings emerged, it seemed possible to call the learning taking place expansive social learning, because it was evident that social learning [31,49-51] had taken place through the expansive learning intervention. It was therefore felt the 'social' aspect of expansive learning is so important and descriptive of the types of learning processes that constitute expansive learning that it needed to be explicitly included. We have therefore kept true to Engeström's theory of expansive learning, and only referred to 'expansive learning' when talking about the theory as it is used in the literature. However when speaking more broadly, for example about expansive learning processes, the words 'expansive social learning' have been used.

Lindley [17,51] provides an in depth view of the type of social learning ontologically congruent with expansive learning, which has supported the research. Particular elements of social learning that were helpful to develop a broad based understanding of social learning in the field of environmental education, and found helpful to this study included: The importance of valuing social learning processes over the outcomes or products of the learning process; needing to bridge the gap between knowing and doing; the importance of changing values, beliefs, ideologies, and assumptions; dissonance as a precondition for learning; the importance of dialogical social learning and thought processes; the necessity of deliberating democratically and equality of participation; structuring deliberations to take into consideration group dynamics; learning with an epistemology orientated to risk; the importance of reflexivity and active and passive social learning; and lastly, understanding the meaning of participation in social learning.

2.3.3. Criteria for What Constitutes Learning in the Organizational and Professional Learning Context of the Research

It was important to define what expansive social learning looks like, in order to recognize it during the analysis of the data. This helped to determine the learning progression of the participants involved in the research project. Engeström and Kerosuo consider the outcomes of expansive learning as being very different, even contrary, to the outcomes of traditional theories of learning: "theories of learning typically speak of the outcomes of learning in terms of knowledge, skills and changed patterns of behaviour. In expansive learning, the outcomes are expanded objects and new collective work practices, including practices of thinking and discourse" [39] (p. 339). Therefore, the following criteria helped to clarify what constituted learning in the context of this study:

1. Participants are able to deeply interrogate the sense, meaning, and their understanding of the context in which they work, and through this questioning begin to co-construct a broader context collectively with the other participants [37].

2. Participants are able to develop an understanding of the historically changing character of the work done in their organization [35,52].

3. Participants develop a broader orientation, perception, and understanding of the activity than that which was initially conceptualized, and additional possibilities are developed that had previously not been thought about [37].

4. Participants are able to develop new knowledge and create new collective work practices [52], including practices of thinking and discourse [39].

5. Participants are able to co-construct new professional practices that cross-traditional professional 'tribal' boundaries [53].

6. Participants are able to collectively look at problems in new ways, and develop new tools to work with these problems, empowering the subjects to transform the activity system and collectively expand the object of the activity [38]. 


\subsubsection{Research Process}

The research was conducted in five phases. Data from all the five phases has been analyzed using inductive, abductive and retroductive modes of inference. Danermark, Ekström, Jacobsen and Karlsson [54] describe inference as "descriptions of various procedures, ways of reasoning and arguing applied when we in science relate the particular to the general. Characteristic of inference is that from one thing conclusions are drawn about something else" (p. 75). All participants in this research process gave their informed consent for inclusion before they participated in the study [17]. The study was conducted in accordance with the Declaration of Helsinki, and the participation and ethical protocol was approved by the Rhodes University Department of Education PhD proposal Higher Degrees Review Committee in November 2010.

Phase 1: The foundation of the Change Laboratory methodology used in expansive learning research is built on the ethnographic data gathered from the activity setting [40], forming step one of the expansive learning cycle (see Figure 3 above). It is here that crucial issues, problems, insights, tensions, dilemmas, and innovative solutions from the past, present, and future practices were recorded through interviews with key individual practitioners and managers before running the first interventionist workshop in phase 2 (step two).

A description, or contextual profile, of the three main activity systems in the Company X Forestry Organization responsible for wetland management was completed. An activity system is a description of the actions of people that are always situated in a historically developed context of collective practice [35]: The activity systems were (1) silviculture foresters; (2) environmental specialists; and (3) community engagement facilitators. Document analysis was conducted from examining 43 historical WWF progress reports. These were written over the past 13 years, during which WWF had worked together with Company $X$ in an effort to strengthen wetland management practices [17]. These quarterly written reports recorded the progress WWF had made in all its work, relative to annual predetermined outcomes and outputs. The tacit knowledge one of the authors had generated over the past 13 years of working with Company $X$, as well as supporting literature such as Company $X$ annual sustainability reports, also informed the development of this contextual picture.

17 semi-structured interviews were held with silviculture foresters, environmental specialists, and community engagement facilitators. This represented approximately $20 \%, 100 \%$, and $25 \%$ respectively of the company $\mathrm{X}$ staff in these job descriptions. These staff were selected from the four geographic areas of the company's forestry operations and formed the core group of research participants that participated during all four phases of the research with whom most of the data would be generated. This number of participants was chosen as it was seen to be a size of group that was most importantly, small enough to be able to work with in a meaningful expansive learning process, but large enough be able to generate sufficient data. Of these seventeen participants four were woman, ten were white and seven black. The low number of woman was due to forestry operations being traditionally dominated by men, rather than a preference to have men as research participants. From each of the geographic areas, there was a minimum of one forester, one environmental specialist, and one community engagement facilitator who had all worked together to varying degrees. An additional two other foresters from two of the areas also participated. The research participants were selected according to the three job descriptions that were responsible for some degree of wetland management in these areas, and individuals within these job descriptions that were most likely to have differing opinions and be willing to express them in a group. Three managers were also selected to participate, including the environmental manager and training manager both from the Company $\mathrm{X}$ head office. The managers were chosen to be able to provide a broader and more strategic insight to the deliberations from a middle level management viewpoint. Where possible, most participating staff were selected on the basis of having a minimum of five years of working experience with the company, to be able to provide greater depth to the historical perspective.

The aim of the interviews was to describe (a) a 'picture' of the three main activity systems involved in wetland management; (b) identify potential challenges and difficulties inhibiting wetland 
sustainability practices; and (c) possible solutions to overcome them. To gain an insight into how these staff were learning and practicing wetland management, a number of questions were explored during the interviews. Although the questions differed slightly according to the three different job descriptions, each question was developed to illuminate a different element of the activity system they were part of (Figure 1): The object of their work; the outcome they were aiming for; the tools that mediated their work in achieving the object of the activity system; the rules that governed the use of the system; the community of practice they worked with; and how the labor was divided within this community. Any challenges and difficulties staff may have experienced that inhibited their learning and practice of wetland management were also discussed. This helped surface the tensions and preliminary contradictions that were evident between the three activity systems. During the interviews, potential solutions were also discussed to deal with the challenges and difficulties that staff thought might strengthen their wetland learning and practice. Each interview averaged a little less than forty minutes, with a total of $101 / 2$ hours of data being captured on a digital voice recorder. All interviews were transcribed, totaling 162 pages.

Second generation CHAT (Section 2.1.1) analysis was used to analyze the interview data to develop the contextual profile or picture of each of the three activity systems. It highlighted the multifaceted inter-relationships between the subject and the community of practice, and placed the mediation focus on the relationships between all the elements of the activity system (Engeström, 2001). This essentially allowed for stronger account of contextual and power relations in the mediation process. Second generation CHAT therefore supported the search for insights into the relationships and interactions that existed within the three activity systems. It did this through examining the relationships and interactions between subjects and the objects they were working on, mediating tools and artifacts that were used, rules that governed the use of the system, the community of practice involved in the system, and the division of labor among those working in the system; all taking place in a cultural and historically constituted activity system [38].

Third generation CHAT (Section 2.1.1; Figure 2) was used as a theoretical lens to analyze the interview data, which allowed for the tensions and contradictions to emerge within and between the three activity systems. After inductively grouping the tensions according to their similarity of theme, we then abductively analyzed the root causes. This resulted in emergence of the twelve contradictions.

Phase 2: This phase consisted of running two formative interventionist workshops a month apart, that were modeled on the Change Laboratory Workshop methodology broadly following the expansive learning cycle outlined in Figure 3 above. These workshop sessions took research participants through the seven different steps of the expansive learning cycle. All the 17 participants who were interviewed in phase 1, took part in both formative interventionist change laboratory workshops.

As step two of the expansive learning cycle, participants reflexively deliberated and analyzed the historically emerging tensions and contradictions identified from the interviews (phase 1) during interventionist workshop \#1. This workshop consisted of eight one-hour sessions held over two days. The eight hours of workshop discussions were audio taped and transcribed, totaling 74 pages. The data generated from phase 1 was used as a mirror to reflect the data captured from those initially interviewed back to the participants, to catalyze interaction between the workshop participants in order to analyze the tensions and preliminary contradictions. It was here that participants began to deconstruct their own frames of how they viewed the issues and were challenged by the views of others in a similar way that Wals [50] describes.

Drawing on Vygotsky's concept of double stimulation, which Engeström [40] sees as playing a crucial role in transformative learning, the mirror data of this first interventionist workshop provided the participants with the first stimulus-when the participants were presented with a problem that they could not solve on their own with their current understanding and knowledge.

Carefully designed questions were used as conceptual tools to stimulate further self-questioning at the beginning of interventionist workshop \#2. This was done to facilitate a deeper analysis of the data by the participants, identifying additional tensions and contradictions as well as their root causes. 
This provided the second stimulus where the questions were used as tools that could be used as an instrument for better understanding the problem, and participants were able to develop solutions to it [55]. The concept of double stimulation was crucial. Using this second stimulus, participants were challenged to use the conceptual tools to reconstruct more meaningful designs of the activity system they were aiming to transform. In other words, the interventionist workshops encouraged participants to expand the object of the activity system (improved wetland management), and develop new tools, rules, and division of labor to provide new solutions overcoming the inhibiting factors that prevented transformational learning from happening. This workshop consisted of five sessions each from one to two hours long, and like the first workshop, was spread over two days. The eight hours of discussions were audio taped and transcribed, totaling 153 pages. This formed the third step of the expansive learning cycle. During the last part of this second interventionist workshop, participants evaluated the newly modeled solutions, to check that they would potentially work in dealing with the contradictions, as the fourth step in the expansive learning cycle.

Phase 3: The fifth step of the expansive learning cycle relied on implementing the modeled solutions as wetland management projects, monitoring the effectiveness of their implementation and understanding what changes in practice had emerged.

After the second interventionist workshop the 17 participants went back to their workplaces to implement the projects over the following eight months, and initiate the new ways of working and learning they had developed. At the end of the eight-month implementation period, five progress review workshops were held in each of the original four business unit areas of Company $X$, as well as an additional new business area where no participants had come from. Each workshop lasted approximately $31 / 2$ hours. The aims of the workshops were to (a) provide an opportunity for the community engagement facilitator, forester and environmental specialist from that area office area who were participating in the research, as well as the environmental manager and training manager from head office, to give feedback on their project implementation progress to the broader staff members of their area office (who numbered from 8-15 staff in each office). These additional staff who were new to the research process included all the community engagement facilitators, foresters and area management staff of the area office; (b) hear what these additional staff who were new to the research process, thought of the expansive learning research that was being undertaken, as well as their views on the tensions and contradictions that emerged from phase one and two of the research; and (c) see whether the involvement of a broader group of Company $X$ staff would encourage and perhaps mobilize additional support to the research participants to carry on implementing their projects, and perhaps catalyze additional improvement in wetland management outside of the projects included in the action and implementation plan developed from the second interventionist workshop. The reason for including the new area office, in addition to the original four area offices, was an attempt to get feedback on the progress and emerging outcomes of the expansive learning process from a broader group of foresters, community engagement facilitators and area management staff who had no previous exposure to the research. Discussions of the five workshops were audio taped totaling $171 / 2$ hours and transcribed totaling 168 pages.

The last grouping of data generated from phase three of the research, was (a) a short $34 \mathrm{~min}$ feedback session was given to the Company $X$ seniors executives of their forestry operations at their request; and (b) as a result of this meeting, the executives requested that a two-hour seminar on the research be held for senior and middle level management at head office. The aim of these two sessions was to (a) provide an overview of the expansive learning research process to the broader management of forestry operations; (b) explain why and how the research was being conducted; (c) share the preliminary results that were beginning to emerge from the research, and (d) hear what the management thought of the research. The two and a half hours of discussions from both the meeting and the seminar were audio taped and only relevant sections of both were transcribed, totaling 20 pages. 
Phase 4: The sixth step of the expansive learning cycle involved interviewing some of the core research participants who took part in phases 1-3, and reflecting on the expansive learning process over the three year period they were involved and what they thought was important to emerge from it. Reflective interviews were held, with nine of the original seventeen core participants consisting of three community engagement facilitators, two foresters, two environmental specialists, as well as two management staff being the environmental manager and a forestry area manager. These staff were selected based on their representativeness from three activity systems in the different area offices, length of time working for the organization, and perceived ability to deeply reflect.

The reflective interviews were conducted in same way as the semi-structured interviews in phase one. Questions that guided conversations with the staff encouraged them to reflect on the expansive learning process over the two and a half year period they were involved. This was done to better understand what change had occurred, and how this change happened. The questions were focused on generating data based a framework of the five different types of changes that had emerged from analysis of the phase 3 data, ranging from tacit/catalytic changes to explicit/actual changes (Section 3.8). Examples of some of the questions included: What has emerged from the expansive learning process for you, and why is it like that? (values, knowledge and thinking, approach, practice, structure); what have been the contributing factors to this? (structure and agency); what are the kinds of struggles that you are having? (structure and agency); how has the expansive learning process affected how you work with colleagues on wetland/environmental management? (approach and practice); how effectively have the action plan projects overcome the contradictions? (structure and agency); were there any barriers inhibiting project implementation? (structure); has wetland/environmental management improved since the expansive learning process started? (practice and structure). Field visits were held after the reflective interviews to see what physical practices had changed.

The seventh and last step of the expansive learning cycle revolved around consolidating the new practices. This step formed part of the reflective interviews. It was thought to be sufficient as those taking part in the nine reflective interviews were considered to be the key participants who understood the purpose of the expansive learning process best, and therefore would be best placed to consolidate the new practices with the rest of the staff. Each interview lasted between 20-30 min long, with a total of a little less than four hours of data being captured on a digital voice recorder. All interviews were transcribed, totaling 55 pages.

Phase 5: This phase was purely an analytical phase that drew on the data generated and analyzed in all the previous phases. In this phase, we drew upon realist social theory and its methodological complement, the morphogenetic framework (Section 2.3.1) to abductively analyze and explain the details of how the change resulting from the change laboratory methodology had happened, or why change has not happened.

In accordance with a critical realist ontology (Section 2.2), which attempts to understand what was happening at the levels of the Real, we used abductive analysis to determine the social and cultural structures that enabled some actions that would otherwise not be possible, and constrained other actions $[47,56]$. This helped to determine the interplay between the emergent properties and powers of the social structures, cultural systems, and the people, to explain how these changes had or had not happened. We then used retroductive analysis to determine what generative mechanisms may have caused the social structures and cultural systems to exist in the first place. This retroductive analysis allowed the researchers to dig deeper into the structures of social reality to reveal these generative or causal mechanisms, to gain an understanding of the real world [43]. In this way the analysis supported the investigation of a deeper reality from which the generative mechanisms and contradictions emerged, which may have existed independently of Company X staff knowing it. This analysis of the data supported answering the 'how' part of the third research question: Can expansive social learning strengthen organizational learning and development, enabling Company $X$ to improve its wetland sustainability practices, and if so how does it do this? 


\section{Results and Discussion}

\subsection{Surfacing Contradictions that Inhibited Wetland Learning and Sustainability Practices}

By using CHAT as a theoretical lens to analyze the data from the interviews of phase 1, a better understanding of the three activity systems was developed and how they interacted with each other. This allowed for the tensions and contradictions within and between the three activity systems to surface. After inductively grouping the tensions according to their similarity of theme, the root causes were then abductively analyzed. This resulted in the emergence of the twelve contradictions inhibiting wetland learning and sustainability practices (Table 1).

Table 1. Contradictions as first identified from interviews in Phase 1.

1. Between the expectation of staff to improve wetland sustainability practices, and no recognized informal and formal learning plan/structure and learning materials in place to strengthen staff learning.

2. Between individuals who recognize the importance of strengthening informal learning, and those who do not because of their attitudes/culture/individual complexity and resistance to change differs.

3. Between the loss of experience and skills from staff leaving, and the lack of a structure/willingness to share wetland knowledge and skills of old timers with newcomers.

4. Between community engagement facilitators, foresters and environmental specialists working in silos on their own jobs and wetland issues, and the Company X's bigger picture of producing sustainably grown timber by staff working together as a team on common wetland issues with a more planned and integrated approach.

5. Between stringent existing performance monitoring systems of e.g., silviculture, safety and alien plant clearing activities, and the lack of any wetland performance monitoring system.

6. Between how Company $\mathrm{X}$ want to manage its wetlands, and how external influences like local communities wants to use and manage the wetland resources.

7. Between the demand for environmental specialist support, and the lack of staff to supply it.

8. Between having dedicated operationally aligned conservation staff to solely take responsibility for wetland and environmental management, and integrating this responsibility into the silviculture foresters' current workload.

9. Between the conservation practices that Company $\mathrm{X}$ has to implement, and practices of neighboring farmers who do as they like.

10. Between implementing general wetland management practices and not knowing exactly what desired state the wetland is being managed for.

11. Between Company $X$ managing the land sustainably now, and how the new land reform owners will manage it in the future.

12. Between senior staff talking the environmental talk, and meaningfully understanding the talk so that they can sincerely walk it.

These 12 contradictions were presented as mirror data in the first formative interventionist workshop, which the workshop participants chose to integrate and reduce to two priority contradictions. The participants felt that contradictions 2,3, and 10 could be integrated into priority contradiction 1 ; and contradictions 6 and 12 could be integrated into priority contradiction 4 . They decided contradictions 5 , $7,8,9$, and 11 were not a priority to deal with, and rather wanted to work with fewer contradictions and put more effort into them. It was therefore contradictions 2 and 4 that the participants chose to address via an expansive learning process. These were reworded as 1) the contradiction between expectations of improvement in wetland management practices and no mechanisms for enabling such learning; and 2) the contradiction between expectation of boundary crossing/integrative work in environmental management and silo structures in the organization. 


\subsection{An Action Plan to Overcome the Two Prioritized Contradictions}

Solutions initially developed during the interviews in phase 1 , were refined and added to during the two interventionist workshops of phase 2, in order to overcome with the two prioritized contradictions. This resulted in an action plan of eleven projects being developed, to stimulate organizational learning and development for improved wetland and environmental management:

Projects strengthening formal learning structures:

- Adapt existing four-day induction program for new employees to be more interactive, have high employee responsibility for completing, spread out over a four-month period, contextually relevant to local area, and include an environmental module.

- Develop a toolbox of environmental education materials with guidance on appropriate education processes for their optimum use.

- Integrate new environmental courses and a toolbox into existing training program for contractors and staff.

Projects encouraging staff collaboration and relational agency:

- Foresters, community engagement facilitators, and environmental specialists to collaboratively develop and implement a wetland project in each of the five geographical areas of Company X.

- Run five field days in the five geographical areas going through management recommendations arising from the recently completed Company X State of Wetlands Health Report.

- Run field days that integrate environmental and forestry operational issues within each of the five geographical areas, as well as between them.

Projects stimulating staff dialogue:

- Ensure that consultants conducting specialist environmental reports meet with forestry operations staff to discuss report and hear staff feedback.

- Ensure that any future Company X environmental policies and procedures to be implemented are discussed with staff on an interactive and 'face to face' basis, and policies or procedures are not only sent out by email for implementation.

- Meet with senior managers to encourage them to hold feedback sessions with staff providing appropriate information on any recent company business of interest.

Projects gaining senior management commitment to action plan:

- Report back to area and senior management on the workshop process and action plan and get commitment to its implementation.

- Meet with senior managers to encourage them to create the space for area managers to motivate their staff to implement the action plan.

\subsection{Results From the Reflective Interviews Held in Phase 4}

The data generated from the nine reflective interviews held in phase 4 was analyzed using the inductive mode of analysis. An analytical memo [57], was developed by grouping those aspects of the conversations that fell into the six categories of change identified from the analysis of the data generated from the five progress review workshops in phase three, as well as any new potential barriers that may have arisen as a result of implementing the new practices. This analytical memo was too long to be included in this paper, but key issues that emerged from it have been integrated across Sections 3.4-3.9.

\subsection{Expansive Social Learning Strengthens Organizational Learning and Development}

The results in Sections 3.4-3.9 have all emerged from a combination of phases 1 to 4 of the research. The research found that expansive social learning processes supported organizational learning 
and development for improved wetland management by (1) strengthening the scope, depth, and sophistication of participant understanding; (2) expanding the ways staff interact and collaboratively work together; (3) democratizing decision making; (4) improving social relations between staff, reducing the power differentials, and creating stronger relationships that previously were separate; (5) enhancing participant reflexivity through deeper understanding of the social structures and cultural systems, and changing them to support improved wetland and environmental practice of staff, and developing the organizational structures and processes to strengthen organizational learning and development. These organizational and professional learning changes that have taken place during the expansive social learning process have been summarized in Table 1 and the following Sections 3.5-3.8.

Table 2 summarizes the progression of learning against the six learning criteria discussed earlier (Section 2.3.3), demonstrating what was evident at the end of the study compared to what was evident at the start of the study. Due to the extensive scale of the data sets and evidence in the original research data analysis, it has not been possible to reproduce detailed examples of the changes that emerged, only the broader key changes. It is important to clarify what we meant by participants developing their 'understanding' of how they viewed the issues they were dealing with. We interpreted this to mean that participants are able to develop new understandings that can be qualified as:

- A deeper understanding of, for example, wetland issues resulting in knowing more about wetlands management;

- A broader understanding, demonstrating that participants have a broader knowledge of wetland management in the organizational context and how different players need to work together;

- An expanded understanding revealing that participants have built on each other's learning and expanded their learning from knowing what they did as an individual to more collaborative, collective, social learning, demonstrating that participants have scaffolded their learning on the comments and dialogue that occurred during the expansive learning workshops;

- An increased sophistication in understanding, signifying that the learning of participants had become more multi-dimensional, more socially integrative, and more organizationally embedded. For example, as the participants began to realize that the contradictions identified inhibiting learning, they started to understand that the social structures and cultural systems of the organization were contributing to this, rather than individual personalities, and that the institutional enabling environment was not present.

Table 2. Summary of the organizational and professional learning changes that took place during the expansive social learning process.

\begin{tabular}{lll}
\hline Changes at End of Research & $\begin{array}{l}\text { Status Quo at the Beginning of } \\
\text { Research }\end{array}$ & $\begin{array}{l}\text { Learning Criteria } \\
\text { Satisfied (Refer to } \\
\text { Section 2.3.3.) }\end{array}$ \\
\hline $\begin{array}{l}\text { Participants improved knowledge in } \\
\begin{array}{l}\text { understanding technical aspects of } \\
\text { wetlands and their management. }\end{array}\end{array}$ & $\begin{array}{l}\text { Participants, particularly community } \\
\text { engagement facilitators, had little } \\
\text { understanding of the technicalities of } \\
\text { wetlands and their management. }\end{array}$ & 3,4 \\
\hline $\begin{array}{l}\text { Participants placed a higher value on } \\
\text { the diverse roles of the different } \\
\text { professional disciplines required for } \\
\begin{array}{l}\text { wetland management, and the } \\
\text { importance of their collaboration. }\end{array}\end{array}$ & $\begin{array}{l}\text { Participants across the different } \\
\text { professional disciplines (foresters, } \\
\text { community engagement facilitators, and } \\
\text { environmental specialists) did not value } \\
\text { each other's roles in wetland } \\
\text { management. }\end{array}$ & 1, 2,3 \\
\hline
\end{tabular}


Table 2. Cont.

\section{Changes at End of Research}

Status Quo at the Beginning of Research
Learning Criteria

Satisfied (Refer to

Section 2.3.3.)
Participants changed the way they thought about how they learnt about wetlands; how they worked and interacted with colleagues; how they understood their colleagues; and how they realized wetland management was important to their specific job descriptions.

A change in discourse on intended agency was identified, signaled by an increased intent to implement more sophisticated solutions developed collaboratively by the participants.

A changed discourse in participant conversations on how wetland and environmental learning now took place, becoming more structured, longer term, and beginning to be institutionalized in Company $\mathrm{X}$.

A changed discourse in conversations that was more collaborative, interactive, and inclusive of each professional discipline.

A changed discourse in conversations of what meaningful learning processes were, and which processes were important for scaffolding a change in wetland and broader environmental practices.
Participants had a simplistic understanding of how they learnt about wetlands, which should be responsible for wetland management, and the importance of collaboration across professional disciplines for improved wetland management.
Participants revealed many problems and tensions inhibiting wetland management but offered only simple solutions with little intent to implement them.

\section{$1,2,3,4$}

A strong discourse of weak environmental learning that was unstructured, occurred on an ad hoc basis when the need arose, and was limited to isolated short-term courses.

\section{$4,5,6$}

A strong discourse of a professional discipline silo approach to communicating, learning, interacting, and working amongst staff.

The discourse of learning was devoid of any understanding of learning processes, and narrowly confined to the problems of staff lacking wetland knowledge, information not being in a usable form, and staff not having the time to learn.
Participant interaction between professional disciplines became more collaborative, personal, empathic of the other, and orientated to learning from each other.

Change in practice of how participants discuss/plan/implement wetland burning with staff across professional disciplines.
Weak staff interaction and collaborative decision making between professional disciplines on wetland and environmental management.

\section{4,5}

4

Change in the practice of how the cattle of neighboring communities graze wetlands on Company $\mathrm{X}$ landholdings.

Change in the practice of developing wetland plans together across professional disciplines.

Change in the practice of communicating new environmental procedure and policies, and specialist report backs.
The poorly managed burning of wetlands was seen to be a key issue of wetland health due to foresters making unilateral decisions.

Cattle grazing was identified as one of the most significant threats to the health $4,5,6$ of Company X's wetlands.

Staff across the different professional disciplines rarely planned and worked together on wetland management $4,5,6$ issues.

Staff work in silos of their professional disciplines, inhibiting collaborative and integrative communications on wetland management.

\section{$4,5,6$}


Table 2. Cont.

\begin{tabular}{|c|c|c|}
\hline Changes at End of Research & $\begin{array}{l}\text { Status Quo at the Beginning of } \\
\text { Research }\end{array}$ & $\begin{array}{l}\text { Learning Criteria } \\
\text { Satisfied (Refer to } \\
\text { Section } 2.3 .3 .)\end{array}$ \\
\hline $\begin{array}{l}\text { Development of environmental training } \\
\text { matrix listing training options begins to } \\
\text { institutionalize staff environmental } \\
\text { learning, and contractor environmental } \\
\text { training developed and implemented. }\end{array}$ & $\begin{array}{l}\text { No formally recognized informal and } \\
\text { formal learning plan or structure and } \\
\text { learning materials in place to strengthen } \\
\text { environmental learning in Company X. }\end{array}$ & 6 \\
\hline $\begin{array}{l}\text { Development of innovative induction } \\
\text { structure and processes begins to } \\
\text { institutionalize environmental learning } \\
\text { for new staff. }\end{array}$ & $\begin{array}{l}\text { No induction process for new staff } \\
\text { existed resulting in a loss of institutional } \\
\text { and environmental knowledge through } \\
\text { a lack of handover from old timers. }\end{array}$ & $3,4,5,6$ \\
\hline
\end{tabular}

3.5. Sophistication of Participant Understanding of the Inhibiting Structural and Cultural Context Increased as the Expansive Learning Cycle Progressed

As the expansive learning cycle progressed from step one to step seven, the research participants developed a deeper and more clear understanding of the tensions and contradictions that were conditioning and inhibiting their wetland learning and practice. This progression in sophistication of understanding also increased as participants developed more sophisticated solutions to deal with the tensions and contradictions. These solutions were aimed at the root causes of the contradictions. This finding supported the start of expansive learning, which Engeström reports the expansive learning cycle will cultivate [36]. The sophistication of understanding emerged from the way the expansive learning process allowed for participants to build on their prior knowledge, which was mobilized during the interviews of phase 1 of the research, and enrich this knowledge with the collective knowledge gained through the dialogic interaction between participants. The dialogic process allowed participants to understand their framing of the issues at an individual level, and then collectively begin to deconstruct meaning of the tensions and contradictions and develop a common understanding of them. Participants went onto collaboratively build on each other's ideas to reconstruct expanded and more meaningful solutions (action plan of eleven projects) to implement that everyone agreed to. This deframing and reframing process echoed the core steps of transformative social learning highlighted by Wals and Heymann [49] as being so important, and is demonstrative of what Harold Glasser [9] called active social learning together with co-learning being its highest form.

This interaction between participants led to horizontal learning taking place between professionals from different activity systems, during the interventionist workshops of phase 2 of the research, aligning with the observations of Engeström [36] and Warmington et al. [53]. They both saw this horizontal learning that took place between professionals from different activity systems, as being a crucial part of expansive learning. The dialogic interaction between participants provided the scaffolding for participants to build on and expand their own ideas, as well as co-constructing new solutions. In this way the group collectively grew their own zone of proximal development [58], as was the case for other researchers too [33,59]. From this deeper and broader understanding, gained through the horizontal learning, and the implementation of the collaborative wetland projects, the shared object of wetland management of the three activity systems of the foresters, community engagement facilitators, and the environmental specialists, was expanded. This highlighted the importance of crossing the boundaries between the different activity systems involved in the expansive learning process for deepening the scope, depth, and sophistication of staff understanding as confirmed by the work of Launis, Virtanen, and Ruotsala [59] and Warmington et al. [53]. It is argued this will most likely result in a greater chance of successfully dealing with the factors hindering wetland management, than if they had attempted to either do this on their own, or collaboratively, but without the support of the expansive learning process. In fact Engeström [60] (p. 38) in his work on different forms of co-configuration states that, "It is horizontal (original emphasis) and dialogical learning that creates knowledge and transforms 
the activity, by crossing boundaries and tying knots between activity systems". The research with Company $\mathrm{X}$ appears to be reflecting this same finding.

\subsection{The Expansive Learning Process Began to Strengthen Democratization of Decision Making}

The process of anonymously presenting the emerging tensions and contradictions as mirror data during the first interventionist workshop contributed towards strengthening the democratization of decision making within the group. This allowed for the ideas of quieter black participants to be noticed and taken up in the discussions by the stronger voiced participants who were predominantly white. The consequence was that the voices of black participants were made visible and allowed for their inclusion and participation. The finding is very important as everybody's voice should be represented irrespective of race, level of education, or gender, even if it does not emerge through them in a public situation. This finding may well be an unintended consequence of the expansive learning process. Barbara Rogoff et al., when researching learning in indigenous American communities, found that that people may sit quietly in group discussions without actively contributing to the discussion, but they are actively listening with intent to act on what they have learnt [61]. This indicates that observation can be a crucial aspect of participation, therefore it is important to not dismiss the quietness of the black participants simplistically as a lack of interest and will to learn, but rather understand the cultural structures that may be influencing how participants act and find ways to overcome them. It therefore a finding that needs to be kept in mind when working in the multi-cultural context that makes up South Africa, where imbalances in power relations continue to exist. This is significant as the culture of black participants could mean stricter rules of engagement between younger and older more experienced staff members, but it is also where the oppressive history of apartheid continues to be felt through the unknowingly dominant white voice despite democratic intentions (Ndletyana, 2003) [62]. A generative mechanism of the 'silent voices' would therefore be the histories of power arising from South Africa's past. However, it would also include the disadvantaged poor quality of the black education system, giving rise to unequal deliberative powers and confidence of individuals, inhibiting the possibility of a deliberative democracy as identified by Young [63] and Sanders [64]. These generative mechanisms therefore go back into the historicity of the society in which Company $X$ is based. The concept of using mirror data as an expansive learning process, can therefore begin to proactively landscape a deliberative democratic approach [65] to growing the reflexivity and change capacity of research participants.

\subsection{Improving Wetland Management Depends on the Critical Relationship Between Wetland Management Practices, Expansive Social Learning Processes, and Organizational Development}

Importantly, with many of the original 12 contradictions identified by the research being between the three activity systems and the institutional setting; and more widely the institutional setting and its surrounding ecology, the critical relationship between wetland management practices, expansive social learning processes, and organizational development was highlighted. The expansive learning process supported Company $X$ staff to collaboratively identify tensions and contradictions that were inhibiting wetland management. It also supported staff to develop possible solutions to deal with the contradictions. However, this alone was most likely insufficient to result in improved wetland management over the long term, especially since most of the contradictions were quaternary contradictions occurring between the activity systems and the institutional setting of Company X. The importance of organizational development emerged as a key-enabling factor. Management capabilities, institutional learning structures, and the impact of organizational restructuring were all highlighted as being critical factors further enabling or disabling the expansive social learning processes necessary for improved wetland management. This strongly correlates with Boreham and Morgan's [24] socio-cultural analysis of organizational learning. Their socio-cultural model identified dialogue as the most important process through which organizations learn, and notes that the relational practices between staff form the social structure that integrates dialogue and organizational learning 
within the company structures. The three relational practices they identified as being critical were (1) providing the spaces for creating shared meaning; (2) reconstituting power relationships between management and staff; and (3) providing the cultural tools to mediate learning. This is exactly what the action plan the Company $\mathrm{X}$ research participants developed called for. Participants asked for managers to provide the space for dialogic discussion; they asked for senior management to request and incentivize area managers to motivate their staff to make the above points happen and measure this; they asked for feedback sessions by management to provide staff with information on broader company issues. This indicates a leveling of the power gradient between management and staff, as well as the recognition that the space needs to be provided to enable informal learning. Staff developed a number of cultural tools to mediate their learning, such as field days, a toolbox of methods and materials to catalyze informal/social learning, an induction process for new and existing staff; and a variety of collaborative projects. Therefore the three relational practices that Boreham and Morgan [24] identified as being so important to organizational learning and development were recognized by the participants as also being important. As evidenced from participants implementing the action plan (Table 2), it can be seen how the participants began to strengthen organizational learning and development in Company $\mathrm{X}$, improving its wetland management practices.

It was concluded that the development of wetland and environmental management knowledge required by Company $\mathrm{X}$ staff is closely related, not just to the workplace situation, but also to the institutional structures and management capabilities. Wetland sustainability practices therefore cannot exist alone. They are dependent on processes such as expansive social learning to strengthen staff dialogue, learning, and improved relational practices and agency, to identify and find solutions to factors inhibiting wetland practice. Anne Edwards $[66,67]$ in her papers on relational agency in professional practice also highlights how expanded forms of professional practice call for an increased ability to work with other practitioners to be able to draw upon distributed resources across different activity systems and professional boundaries. She argues that increased relational agency results in more efficient professional practice. As evident from the development the action plan of eleven projects, Company $\mathrm{X}$ participants were able to develop and implement a plan to support the strengthening of staff relational agency.

Wetland sustainability practices are also dependent on the development of the organization to put in place the institutional structures enabling the social learning processes required for improved wetland management. These are processes that enable the 'assembling of the collective' [1]. The relationship between the wetland sustainability practices, expansive social learning processes, and organizational development is therefore critical to improved wetland management.

\subsection{Five Types of Changes Emerged from the Research Ranging from Tacit Catalytic Changes to Explicit Actual Changes}

Five types of changes emerged from the research: (1) Changes in knowledge, values, and thinking, (2) changes in discourse, (3) changes in approach, (4) changes in practice, and (5) changes in structure. These changes (outlined in Figure 5 below, with summary evidence in Table 2 ranged on a visibility scale; from the changes in structure and practice being quite explicit on the one hand, to the changes in approach, discourse, knowledge, values, and thinking being more tacit on the other hand. This was an important finding, as most often it is the explicit changes that tend to be noticed and recorded in organizational and/or social-ecological system change. However the tacit changes have taken place even if they are not as easy to see or measure; hence they are often ignored or go largely unnoticed. The findings also show that tacit changes are emerging changes that appear to be a prerequisite enabling the explicit changes to take place in organizational settings. Tacit changes also have the potential to catalyze further changed practices and structures in the future. They can therefore be termed catalytic changes [68], as they have the potential for catalyzing future change. 


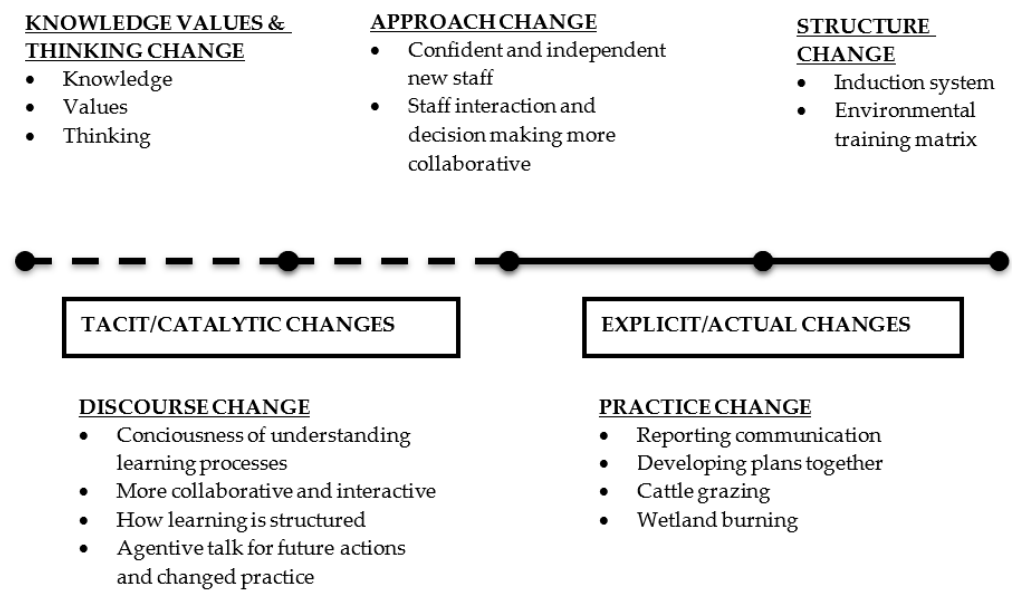

Figure 5. Types of changes on a visibility scale, ranging from those being tacit and catalytic to those being explicit and actual.

This finding is important for environmental education since it is characteristically a catalytic activity, which seeks to develop the agency of people to act on environmental issues, with most of these actions only taking place in the future, as highlighted by Wals [50] and Lotz-Sisitka and Hlengwa [68]. This means that success of the expansive learning process in dealing with the contradictions, cannot only be judged only by the more explicit changes that have been documented such as changes in structures and practices, but also by the potential future change that the tacit changes may catalyze. These may ultimately be of greater consequence than the initial explicit changes that took place, although the explicit changes may also go on to catalyze additional future changes themselves. Lotz-Sisitka and Hlengwa [68] also found that the notion of catalytic change and potential future actions was important when monitoring the effectiveness of environmental education training programs, when they linked catalytic change to how the evidence of current change would most probably be expanded in the future. This they highlight "is useful for ongoing monitoring; and for understanding the longer term impact and change that is associated with education and training interventions" (p. 17). Such tacit changes therefore also have the potential to bring about change in the way people practice wetland management in the future; as was also shown over the period of the expansive learning process. Therefore tacit changes are very important indicators for determining the potential changes that might happen in the future and for 'assembling the collective' in organizational change settings. New tools, rules, and a stronger community of practice and division of labor, have emerged from the three interacting and changing activity systems, as indicated by the five types of changes. The object they were working on, has therefore become collectively meaningful to the foresters, community engagement facilitators, and environmental specialists. This is an important indicator of expansive learning having occurred, as Engeström and Kersosuo [39] explain that "in expansive learning, the outcomes are expanded objects and new collective work practices, including practices of thinking and discourse" (p. 339).

\subsection{Expansive Social Learning Provided a Platform to Catalyze the Morphogenesis of Organizational Learning and Development}

Analysis of how the changes in organizational learning and development in relation to wetland and environmental management came about showed that it was through a morphogenetic process. The expansive learning cycle provided a platform to scaffold and support open-ended environmental learning processes that are deliberative and potentially catalytic, and strengthened reflexivity for changed wetland practices. This catalyzed the socio-material/socio-cultural-agential interaction (T2-T3 in Figure 6) required for morphogenesis, through enabling a safe learning 'space' with associated tools to act as the starting point for the interaction and new practices that demonstrated new human-non-human relations in the form of improved wetland management practices. It is these types of relations that 
Latour [1] suggested were how humans in their individual and organizational contexts ought to be re-thinking their notion of the collective.

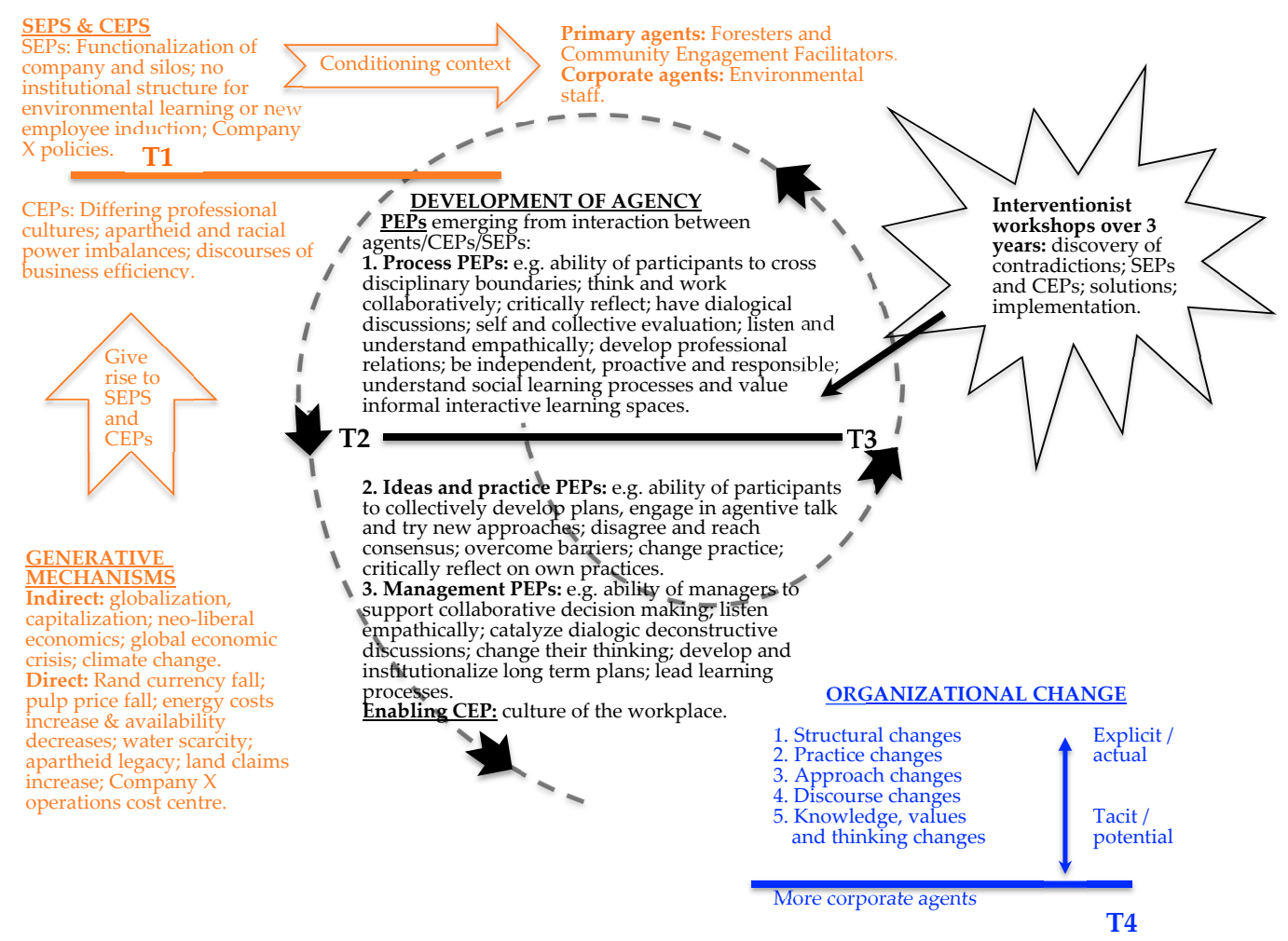

Figure 6. The morphogenesis of organisational learning and development for changed wetland and environmental management.

Interventionist workshops catalyzed engagement of the participants with the properties and powers of the social structures and cultural systems (present at T1 in Figure 4) that were conditioning the context in which the Company X staff were learning and practicing. Archer [45] refers to these as cultural emergent properties and powers (CEPs); and structural emergent properties and powers (SEPs). As mentioned Section 2.3, she argues that it is necessary to analytically separate cultural emergent properties and powers (e.g., in this research we identified culturally institutionalized power relations 'left over' from apartheid days as being a particularly powerful CEP) and structural emergent properties and powers (e.g., in this research we identified functionalization of the company into siloed departments as being one of the more intractable SEPs) in research to avoid conflation; and thus our understanding of how organizational change takes place via processes such as expansive social learning. Archer also differentiates personal emergent properties (PEPs) of agents (e.g., the willingness to engage in multidisciplinary groups, care about wetlands, critically reflect, and engage in dialogue were some of the influential PEPs in this study) and their influence in the change process. During the expansive social learning interactions (T2-T3), the personal emergent properties and powers of participants were activated and came into relationships with those of the social structures and cultural systems, as they began to interact and shape one another. Crucially, the deliberative engagement of participants with the tensions and contradictions catalyzed the activation of these powers. This required embracing a deliberative democratic approach to supporting the reflexivity and change capacity of agents, which Benhabib [65] advocates as being so important to change processes. This interaction strengthened participant reflexivity over the three-year intervention research period, enabled participants to deeper understand the inhibiting structures, and to develop and implement the solutions that resulted in the five different types of changes (T4). At the same time the participants experienced a change in themselves, through a change in knowledge, thinking, values, discourse, and 
the way they approached their work. Double morphogenesis was therefore achieved, as the participants began to change the structures, they themselves were also changed in the process, which Archer [46] predicts will happen. Without the expansive social learning processes, this would not have happened.

The research consequently revealed that expansive social learning could provide a space for seeding or catalyzing organizational development, organizational learning, and organizational change processes through enhancing agential reflexivity (summarized in Figure 6 below). The emergent properties and powers consolidate an understanding of how the seeding and emerging changes are taking place within this expansive learning space.

Figure 6, which shows how the CEPs, SEPs, and PEPs are interacting to bring about the different types of change, is the environmental learning process. This demonstrates how proactive steps can be taken to structure learning in open and reflexive ways using expansive social learning processes as shown in this research, to encourage the emergence of properties and powers such as these, which can support the emergence of morphogenesis. Importantly, it also means that the emergence of properties and powers such as these can also be monitored to determine how the change is progressing. Figure 7 below, highlights how the seven steps or learning actions of the expansive learning cycle (Figure 3 above), as implemented in this research, may be used to proactively work with the morphogenetic process to support this change. This overlay of the expansive learning process with the morphogenetic process demonstrates how environmental education researchers can proactively work with the sociology potential of morphogenesis to potentially enable and bring about changes in environmental learning and practice. This is a different approach to how Archer $[45,46]$ uses the morphogenetic framework. She uses it to describe how change has happened over a period of time in the past by looking at existing practice. She does not work on how the social processes of learning can be proactively used as mobilizers of potential morphogenesis [68]. However, this research project has revealed morphogenesis that has occurred as a result of a carefully structured and planned developmental work research intervention, designed to possibly bring about change using the expansive learning methodology as a platform. This research showed that change was 'seeded' through such a process [68].

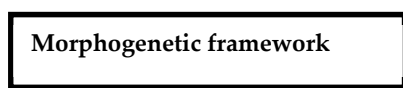

Structural conditioning

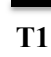

T1
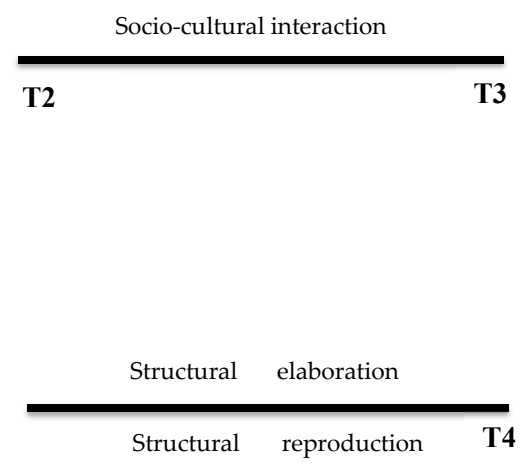

Expansive learning process

INTERVIEWS and CONTEXTUAL PROFILE Step 1: Questioning

WORKSHOPs \#1 and 2, PROJECTS and WORKSHOPS \#3

Step 2: Analysis Step 3: Modeling new solutions Step 4: Examining and testing new models

Step: 5: Implementing new models

WORKSHOPS \#3 and REFLECTIVE INTERVIEWS

Step 6: Reflecting on process and results Step 7: Consolidation and generalizing the new practice

Figure 7. An overlay of the expansive learning process, as implemented in this research, with the morphogenetic process. 


\section{Conclusions}

Besides concluding that the expansive learning process contributes to organizational learning and change, albeit in smaller, often non-linear cycles of change; the research was able to identify the nature of the changes that appeared to be significant. Additionally, we were able to explain how the changes occurred via the interaction of structural emergent properties and powers; cultural emergent properties and powers; and personal emergent properties and powers of agents; i.e., how the morphogenesis process was constituted in relation to socio-cultural and socio-material context/s. Additionally, the research concluded that expansive social learning can provide an environmental education platform to proactively work with the sociological potential of morphogenesis to bring about future change. This took place via an open-ended participatory and reflexive expansive learning process that is also coupled to political ecology changes in organizations. It did not occur via earlier approaches of social engineering or technicism, but rather through processes of deliberative democracy and collective actions that occur at the interface of activity systems and the socio-material. The open-ended nature of the process was therefore crucial. This meant it was not possible to predict if or how the learning would lead to specific changes at the start of the expansive learning process.

We found that admitting a stronger focus on the socio-material into the CHAT framework was brought about by a critical realist ontological perspective, and by the nature of the wetland degradation (social-ecological/political-ecology) concerns that formed the focus of the research. Such an approach to learning involves processes of deliberative democracy akin to those explained by Benhabib [65], but also to those explained by Latour [1] in which both the human and non-human are assembled in a 'new collective'.

As a scholastic piece of work, this research has contributed to the environmental education research field by enhancing an understanding of how change orientated learning can take place. The morphogenetic analysis of the research has deepened earlier work in the CHAT and expansive learning field on understanding how social interaction with the contradictions has the potential to bring about social change. This has been achieved through demonstrating how expansive social learning can be used as a formative interventionist platform and methodological means to create the environmental education 'space' to proactively work with the sociology potential of morphogenesis to bring about future changes in environmental practice. It has demonstrated that when used appropriately, this learning space has the potential to seed or catalyze organizational development, organizational learning, and organizational change processes through enhancing participant reflexivity.

Author Contributions: Study design: D.L. and H.L.-S.; Data collection: D.L.; Data analysis; D.L. and H.L.-S.; Manuscript writing and editing: D.L. and H.L.-S.; Supervision: H.L.-S.

Funding: This PhD research was partly supported by the not-for-profit South African conservation organisations, WESSA and WWF-SA.

Acknowledgments: Thanks to Jim Taylor and Eureta Rosenberg who provided the inspiration for this research. Heila Lotz-Sisitka and Rob O'Donoghue were wonderful in providing such insightful and deep thinking advice, and opening up David Lindley's mind to new ideas and ways of thinking. Thanks also go to Mutizwa Mukute whose thesis motivated and guided my research. Immense thanks to my wife Ros Lindley for tirelessly and painfully transcribing countless interviews and workshops.

Conflicts of Interest: The authors declare no conflict of interest. The funders had no role in the design of the study; in the collection, analyses, or interpretation of data; in the writing of the manuscript, or in the decision to publish the results.

\section{References}

1. Latour, B. Politics of Nature. How to Bring the Sciences into Democracy; Harvard University Press: Cambridge, MA, USA, 2004; ISBN 0-674-01347-6.

2. World Resources Institute, Millennium Ecosystem Assessment. Ecosystems and Human Well-Being: Wetlands and Water Synthesis; World Resources Institute, Millennium Ecosystem Assessment: Washington, DC, USA, 2005. 
3. Russi, D.; Ten Brink, P.; Farmer, A.; Badura, T.; Coates, D.; Förster, J.; Kumar, R.; Davidson, N. The Economics of Ecosystems and Biodiversity for Water and Wetlands; Report; Ramsar: Gland, Switzerland, 2013.

4. Kotze, D.; Breen, C.M.; Quinn, N. Wetland losses in South Africa. In Wetlands of South Africa; Department of Environmental Affairs and Tourism: Pretoria, South Africa, 1995; pp. 263-272.

5. Driver, A.; Sink, K.; Nel, J.; Holness, S.; Van Niekerk, L.; Daniels, F.; Jonas, Z.; Majiedt, P.; Harris, L.; Maze, K. National Biodiversity Assessment 2011: An Assessment of South Africa's Biodiversity and Ecosystems; Synthesis Report; South African National Biodiversity Institute, Department of Environmental Affairs: Pretoria, South Africa, 2012.

6. Tilbury, D. Education for Sustainable Development: An Expert Review of Processes and Learning; UNESCO: Paris, France, 2011.

7. Lotz-Sisitka, H.; Le Grange, L. Learning to Live with it? Troubling Education with Evidence of Global Climate Change. In Climate Change and Philosophy; Irwin, R., Ed.; Continuum: London, UK, 2010; ISBN 978-0-8264-4065-5.

8. Reed, M.; Evely, A.; Cundill, G.; Fazey, I.; Glass, J.; Laing, A.; Newig, J.; Parrish, B.; Prell, C.; Raymond, C.; et al. What is Social Learning? Ecol. Soc. 2010, 15, 1-10. [CrossRef]

9. Glasser, H. Minding the Gap: The Role of Social Learning in Linking our Stated Desire for a More Sustainable World to our Everyday Actions and Policies. In Social Learning Towards a Sustainable World; Wals, A., Ed.; Wageningen Academic Publishers: Wageningen, The Netherlands, 2007; ISBN 978-90-8686-031-9.

10. Mitsch, W.; Gosselink, J. Wetlands, 4th ed.; John Wiley: New York, NY, USA, 2007; ISBN 978-0-471-69967-5.

11. Gush, M.; Scott, D.; Jewitt, G.; Schulze, R.; Lumsden, T.; Hallowes, L.; Gorgons, A. Estimation of Streamflow Reductions Resulting from Commercial Afforestation in South Africa; Report TT173/02; Water Research Commission: Pretoria, South Africa, 2002.

12. Dye, P.; Jarmain, C.; Le Maitre, D.; Everson, C.; Gush, M.; Clulow, A. Modelling Vegetation Water Use for General Application in Different Categories of Vegetation; Report TT1319/1/08; Water Research Commission: Pretoria, South Africa, 2008.

13. South African Government Department of Water Affairs and Forestry. National Water Act; South African Government Department of Water Affairs and Forestry: Pretoria, South Africa, 1998.

14. Lindley, D. WWF Progress Reports: January 1997 to November 2009; World Wide Fund for Nature: Cape Town, South Africa, 2009.

15. Walters, D.; Kotze, D.; Job, N. Company X State of Wetlands Report; Research Report; Wildlife and Environment Society of South Africa: Pretoria, South Africa, 2011.

16. Lindley, D. Reflexively Exploring Better Wetland Management with Company X; Masters Coursework Assignment; Rhodes University, Education Department: Grahamstown, South Africa, 2009.

17. Lindley, D. Can Expansive (Social) Learning Processes Strengthen Organisational Learning for Improved Wetland Management in a Plantation Forestry Company, and If So How? A Case of Company X, South Africa. Ph.D. Thesis, Rhodes University, Grahamstown, South Africa, 2014.

18. Senge, P. The Fifth Discipline: The Art and Practice of the Learning Organisation; Doubleday: New York, NY, USA, 1990; ISBN 0307477649.

19. Easterby-Smith, M.; Araujo, L. Organizational learning: Current debates and opportunities. In Organizational Learning and the Learning Organization; Easterby-Smith, M., Burgoyne, J., Araujo, L., Eds.; Sage: London, UK, 1999; pp. 1-21. ISBN 13 978-0761959168.

20. Popper, M.; Lipshitz, R. Organisational learning: Mechanisms, culture and feasibility. Manag. Learn. 2000, 31, 181-196. [CrossRef]

21. Elkjaer, B. Organisational learning: The 'Third Way'. Manag. Learn. 2004, 45, 419-434. [CrossRef]

22. Bapuji, H.; Crossan, M. From questions to answers: Reviewing organisational learning research. Manag. Learn. 2004, 35, 397-417. [CrossRef]

23. Rebelo, T.; Gomes, A. Organizational learning and the learning organization: Reviewing evolution for prospecting the future. Learn. Organ. 2008, 15, 294-308. [CrossRef]

24. Boreham, N.; Morgan, C. A socio-cultural analysis of organisational learning. Oxf. Rev. Educ. 2004, 30, 307-325. [CrossRef]

25. Peters, T. Thriving on Chaos: Handbook for a Management Revolution; Alfred A. Knopf: New York, NY, USA, 1987; ISBN 13 978-0060971847. 
26. Fenwick, T. Questioning the concept of the learning organization. Knowledge Power and Learning; Paechter, C., Preedy, M., Scott, D., Soler, J., Eds.; Paul Chapman: London, UK, 2001; pp. 74-88. ISBN 0-7619-6936-5.

27. Örtenblad, A. On differences between organizational learning and learning organisation. Learn. Organ. 2001, 8, 125-133. [CrossRef]

28. Örtenblad, A. Of course organisations can learn! Learn. Organ. 2005, 12, 213-218.

29. Elkjaer, B. In search of social learning theory. In Organizational Learning and the Learning Organization; Easterby-Smith, M., Burgoyne, J., Araujo, L., Eds.; Sage: London, UK, 1999; pp. 75-91. ISBN 13 978-0761959168.

30. Brown, J.; Duguid, P. Organizational learning and communities of practice: Towards a unified view of working, learning, and innovation. Organ. Sci. 1991, 2, 40-57. [CrossRef]

31. Lotz-Sisitka, H.; Mukute, M.; Belay, M. The 'Social' and 'Learning' in Social Research: Avoiding Ontological Collapse with Antecedent Literatures as Starting Points for Research. In (Re) Views on Social Learning Literature: A Monograph for Social Learning Researchers in Natural Resources Management and Environmental Education; Lotz-Sisitka, H., Ed.; Rhodes University: Grahamstown, South Africa, 2012; ISBN 978-1-919991-81-8.

32. Lee, Y.; Roth, W. The individual/collective dialectic in the learning organisation. Learn. Organ. 2007, 14, 92-107. [CrossRef]

33. Engeström, Y. Learning by Expanding: An Activity Theoretical Approach to Developmental Research; Orienta-Konsultit: Helsinki, Finland, 1987; ISBN 9519593322.

34. Lave, J.; Wenger, E. Situated Learning: Legitimate Peripheral Participation; University of Cambridge Press: Cambridge, UK, 1991; ISBN 9780521423748.

35. Virkkunen, J.; Kuutti, K. Understanding Organizational Learning by Focusing on "Activity Systems". Account. Manag. Inf. Technol. 2000, 10, 291-319. [CrossRef]

36. Engeström, Y. Activity Theory as a Framework for Analysing and Redesigning Work. Ergonomics 2000, 43, 960-974. [CrossRef] [PubMed]

37. Engeström, Y. Expansive Learning at Work: Toward an Activity Theoretical Reconceptualisation. J. Educ. Work 2001, 14, 133-156. [CrossRef]

38. Daniels, H. Vygotsky and Research; Routledge: Abingdon, UK, 2008; ISBN 0-203-89179-1.

39. Engeström, Y.; Kerosuo, H. From Workplace Learning to Inter-organizational Learning and Back: The Contribution of Activity Theory. J. Workplace Learn. 2007, 19, 336-342. [CrossRef]

40. Engeström, Y.; Sannino, A. Studies of expansive learning: Foundations, findings and future challenges. Educ. Res. Rev. 2010, 5, 1-24. [CrossRef]

41. Engeström, Y.; Kerosuo, H.; Kajamaa, A. Beyond Discontinuity: Expansive Organisational Learning Remembered. Manag. Learn. 2007, 38, 310-336. [CrossRef]

42. Bhaskar, R. A Realist Theory of Science; Routledge: Abingdon, UK, 2008; ISBN 0-415-45494-8.

43. Delanty, G. Concepts in the Social Sciences: Philosophical and Methodological Foundations, 2nd ed.; Open University Press: Maidenhead, UK, 2005; ISBN 0-335-21722-2.

44. Sayer, A. Realism and Social Science; Sage: London, UK, 2000; ISBN 0-7619-6124-0.

45. Archer, M. Realist Social Theory: The Morphogenetic Approach; Cambridge University Press: Cambridge, UK, 1995; ISBN 0-521-48176-7.

46. Archer, M. Being Human: The Problem of Agency; Cambridge University Press: Cambridge, UK, 2000; ISBN 0-521-79564-8.

47. Carter, B.; New, C. Introduction: Realist Social Theory and Empirical Research. In Making Realism Work: Realist Social Theory and Empirical Research; Carter, B., New, C., Eds.; Routledge: Abingdon, UK, 2004; ISBN 0-415-30061-4.

48. Wheelahan, L. Blending Activity Theory and Critical Realism to Theorise the Relationship Between the Individual and Society and the Implications for Pedagogy. Stud. Educ. Adults 2007, 39, 183-196. [CrossRef]

49. Wals, A.; Heymann, F. Learning on the Edge: Exploring the Change Potential of Conflict in Social Learning for Sustainable Living. In Educating for a Culture of Social and Ecological Peace; Wenden, A., Ed.; University of New York Press: New York, NY, USA, 2004; ISBN 0-7914-6173-4.

50. Wals, A. Learning in a Changing World and Changing in a Learning World: Reflexively Fumbling Towards Sustainability. S. Afr. J. Environ. Educ. 2007, 24, 35-45.

51. Lindley, D. Elements of Social Learning Supporting Transformative Change. S. Afr. J. Environ. Educ. 2015, 31, 50-64. 
52. Daniels, H.; Leadbetter, J.; Warmington, P.; Edwards, A.; Martin, D.; Popova, A.; Apostolov, A.; Middleton, D.; Brown, S. Learning in and for Multi-Agency Working. Oxf. Rev. Educ. 2007, 33, 521-538. [CrossRef]

53. Warmington, P.; Daniels, H.; Edwards, A.; Leadbetter, J.; Martin, D.; Middleton, D.; Parson, S.; Popova, A. Surfacing contradictions: Intervention workshops as change mechanisms in professional learning. In Proceedings of the British Education Research Association Annual Conference, Pontypridd, UK, 14-17 September 2005.

54. Danermark, B.; Ekström, M.; Jakobsen, L.; Karlsson, J. Explaining Society; Routledge: Oxon, UK, 2002; ISBN 0-203-99624-0.

55. Mukute, M. Exploring and Expanding Learning Processes in Sustainable Agriculture Workplace Contexts. Ph.D. Thesis, Rhodes University, Grahamstown, South Africa, 2010.

56. Benton, T.; Craib, I. Critical realism and the social sciences. In Philosophy of Science: The Foundations of Philosophical Thought; Benton, T., Craib, I., Eds.; Palgrave: Basingstoke, UK, 2001; pp. 119-139. ISBN 13 978-0230242609.

57. Bassey, M. Case Study Research in Educational Settings; Open University Press: Buckingham, UK, 1999; ISBN 109780335199846.

58. Vygotsky, L. Mind in Society: The Development of Higher Psychological Processes; Harvard University Press: Cambridge, MA, USA, 1978; ISBN 0-674-57629-2.

59. Launis, K.; Virtanen, T.; Ruotsala, R. Change workshops as a tool in organisational boundary crossing. In Proceedings of the 5th International Conference on Researching Work and Learning, Cape Town, South Africa, 2-5 December 2007.

60. Engeström, Y. Enriching the theory of expansive learning: Lessons from journeys toward coconfiguration. Mind Cult. Act. 2007, 14, 23-39. [CrossRef]

61. Rogoff, B.; Paradise, R.; Mejia Arauz, R.; Correa-Chavez, M.; Angelillo, C. Firsthand learning through intent participation. Ann. Rev. Psychol. 2003, 54, 175-203. [CrossRef] [PubMed]

62. Ndletyana, D. The impact of culture on team learning in a South African context. Adv. Dev. Hum. Resour. 2003, 5, 84-102. [CrossRef]

63. Young, M. Communication and the Other: Beyond deliberative democracy. In Democracy and Difference: Contesting the Boundaries of the Political; Benhabib, S., Ed.; Princeton University Press: Princeton, NJ, USA, 1996; pp. 120-135. ISBN 13 978-0691044781.

64. Sanders, L. Against deliberation. Political Theory 1997, 25, 347-376. [CrossRef]

65. Benhabib, S. Towards a Deliberative Model of Democratic Legitimacy. In Democracy and Difference: Contesting the Boundaries of the Political; Benhabib, S., Ed.; Princeton University Press: Princeton, NJ, USA, 1996; ISBN 0-691-04479-1.

66. Edwards, A. Relational Agency: Learning to be a resourceful practitioner. Int. J. Educ. Res. 2005, 43, 168-182. [CrossRef]

67. Edwards, A. Relational Agency in professional practice: A CHAT analysis. Actio Int. J. Hum. Act. Theory 2007, 1, 1-17.

68. Lotz-Sisitka, H.; Hlengwa, A. 'Seeding Change': 2011 International Training Programme: Education for Sustainable Development in Higher Education: Africa Regional Support. Processes and Outcomes; Research Report; Rhodes University, Education Department: Grahamstown, South Africa, 2011.

(C) 2019 by the authors. Licensee MDPI, Basel, Switzerland. This article is an open access article distributed under the terms and conditions of the Creative Commons Attribution (CC BY) license (http://creativecommons.org/licenses/by/4.0/). 